\title{
Theoretical modeling and simulation of AGMD and LGMD desalination processes using a composite
}

\section{membrane}

\section{Baek-Gyu Imª, Jung-Gil Lee ${ }^{\text {a,b }}$, Young-Deuk Kim ${ }^{\mathrm{c}}$, Woo-Seung Kim ${ }^{\mathrm{c}, *}$}

${ }^{a}$ Department of Mechanical Engineering, Hanyang University, 222 Wangsimni-ro, Seongdong-gu, Seoul 04763, Republic of Korea

${ }^{b}$ King Abdullah University of Science and Technology (KAUST), Water Desalination and Reuse Center (WDRC), Biological and Environmental Science and Engineering Division (BESE), Thuwal 23955-6900, Saudi Arabia

${ }^{c}$ Department of Mechanical Engineering, Hanyang University, 55 Hanyangdaehak-ro, Sangnok-gu, Ansan, Gyeonggi-do 15588, Republic of Korea

\footnotetext{
* Corresponding author. E-mail address: wskim@ @anyang.ac.kr (W.-S. Kim); Tel.: +82-31-400-5248; Fax: +82$31-418-0153$
}

\begin{abstract}
Most previous studies of air- and liquid-gap membrane distillation (AGMD and LGMD) processes using a composite membrane have been focused on an experimental approach. In this paper, rigorous theoretical investigations of the AGMD and LGMD processes were performed with a flat sheet type module using a composite membrane comprised of a polytetrafluoroethylene (PTFE) active layer and a polypropylene (PP) support layer. The model predictions were verified by comparing with measured data, where good agreement between the prediction results and experimental data was obtained. It was observed that as the gap size increased the AGMD permeate flux decreased exponentially with increased diffusion resistance. On the other hand, the LGMD permeate flux decreased exponentially and then increased asymptotically after attaining a minimum at a certain liquid-gap size $(5-7 \mathrm{~mm})$. This phenomenon was due to the onset and enhancement of a natural convection, resulting in an improvement in heat and mass transfer in the liquid gap.
\end{abstract}

Keyword: Air-gap membrane distillation, Liquid-gap membrane distillation, Desalination, Heat and mass transfer, Composite membrane 


\section{Introduction}

Membrane distillation (MD) is a thermally-driven separation process in which only water vapors or other volatile molecules move through porous hydrophobic membranes. Compared to conventional desalination processes such as multi-stage flash (MSF), multi-effect distillation (MED), and reverse osmosis (RO), several core advantages of the MD process are; (i) low sensitivity to salt concentration, (ii) theoretically $100 \%$ salt rejection, and (iii) low operating temperature and pressure [1,2]. Such a MD process can be classified into: (i) direct-contact membrane distillation (DCMD), (ii) air-gap membrane distillation (AGMD), (iii) vacuum membrane distillation (VMD), and (iv) sweeping-gas membrane distillation (SGMD).

Among the MD configurations, DCMD has been the most widely studied due to its simple configuration, the capability to produce a relatively high flux, and it has no additional equipment such as an external condenser to condense water vapor, which is required in VMD and SGMD [3]. However, the DCMD process has the drawback of a relatively higher heat loss over other MD configurations [4]. The heat loss is mainly caused by the heat conduction through a single hydrophobic membrane as well as the heat losses to the ambient through the module structure. Reduced heat loss in the MD process can be achieved by (i) increasing the pore size, porosity and thickness of the membrane, and (ii) decreasing the thermal conductivity of the membrane. However, the latter cannot be fulfilled as most hydrophobic polymer materials have very similar thermal conductivities. Meanwhile, in the former case, there exists a conflict between low conductive heat loss (with a high membrane thickness) and high mass transfer (with a low membrane thickness). In conclusion, it is difficult for a single hydrophobic membrane to meet the requirements of an ideal membrane for the MD process, i.e., high mass transfer and low conduction heat loss, with a single hydrophobic membrane [5]. Therefore, in order to avoid the conflict mentioned above, a microporous hydrophobic/hydrophilic (or hydrophobic/hydrophobic) composite membrane that consists of a thin active layer for high mass transfer and a thick support layer for low conductive heat loss can be employed. Most studies on composite membranes have been experimentally carried out [5-11], while a few papers based on theoretical approaches have been reported [5,10,11]. Furthermore, the aforementioned theoretical researches were mainly focused on the DCMD process using a composite membrane and the developed models were based on a length-averaged lumped model, which disregards spatial variations of both the feed and permeate flows [12].

The DCMD module configuration consists of two stream flows separated by a thin membrane with a hydrophobic nature. However, this configuration is vulnerable to conductive heat losses. Among all of the possible MD processes, one of the alternatives to cope with conductive heat loss is the AGMD, which constitutes 
an air gap between the membrane and cooling plate, resulting in lower conductive heat loss and a higher thermal efficiency. In addition, if a low temperature feed is used as a cooling stream, the latent heat can be recovered through the condensation of the vapors on the cooling plate [3]. On the contrary, AGMD has a lower permeate flux compared to DCMD due to the high mass transfer resistance in the air gap [13]. In this regard, liquid-gap membrane distillation (LGMD) has been suggested to overcome the lower permeate flux and higher heat loss in AGMD and DCMD, respectively. LGMD utilizes a liquid gap between the membrane and cooling plate, which is typically filled with a liquid. Recently, Francis et al. [14] attempted to fill the gap with different types of materials, such as a sponge (polyurethane), DI water, sand, and polypropylene mesh. It was found that the permeate flux of LGMD is higher than that of AGMD at the same operating conditions. Furthermore, an improved LGMD permeate flux was achieved due to an enhanced natural convection in the liquid gap with increasing liquid gap thickness from $9 \mathrm{~mm}$ to $13 \mathrm{~mm}$. Essalhi et al. [15] also carried out an experimental investigation of AGMD and LGMD using a composite membrane. The permeate flux of LGMD was slightly higher $(2.2-6.5 \%)$ than that of AGMD at the feed inlet temperatures of $35-80{ }^{\circ} \mathrm{C}$ and an air/liquid gap of $4.532 \mathrm{~mm}$. Therefore, there is a dearth of literature for both comprehensive experimental and theoretical studies of the LGMD process.

In this study, theoretical investigations were performed to attain more comprehensive and systematic understanding of the heat and mass transfer phenomena in the AGMD and LGMD processes using a commercial hydrophobic microporous composite membrane with an active layer of polytetrafluoroethylene (PTFE) and a scrim-backing support layer of polypropylene (PP). The main objective of this study was to develop the integrated numerical analysis model of AGMD and LGMD processes, which consists of mass, momentum, species, and energy balances of both the bulk feed and coolant flows coupled with the heat and mass transfer of water vapor through the membrane and air/liquid gap. The theoretical model developed in this study was validated with experimental data obtained from the literature $[14,16]$. Further studies were carried out to identify the effects of the feed and coolant temperatures, the feed and coolant flow rates, surface porosity, and natural convection on the permeate flux.

\section{Theoretical models}

The mathematical models for the AGMD and LGMD processes were formulated to include heat and mass transfers. In both processes, a flat-sheet composite membrane is in direct contact with the feed stream, and an air or liquid gap is interposed between the membrane and a condensation surface while a coolant flows in the 
direction countercurrent to the feed. The mass and heat transfer mechanisms in the AGMD and LGMD processes are illustrated in Fig. 1. For the simulation, the following assumptions are employed: (i) steady-state incompressible flow, (ii) negligible heat loss to the ambient environment, (iii) only water vapor permeation through membrane pores, (iv) atmospheric pressure in the air gap, and (v) unidirectional Newtonian fluid flow in feed and coolant side. The SEM images of the composite membrane used in the present work are shown in Fig. 2 $[12,14,16,41]$. It is shown that the knot-fibril net structured PTFE active layer (dark gray) was partially covered by the PP scrim-backing support layer (white gray).

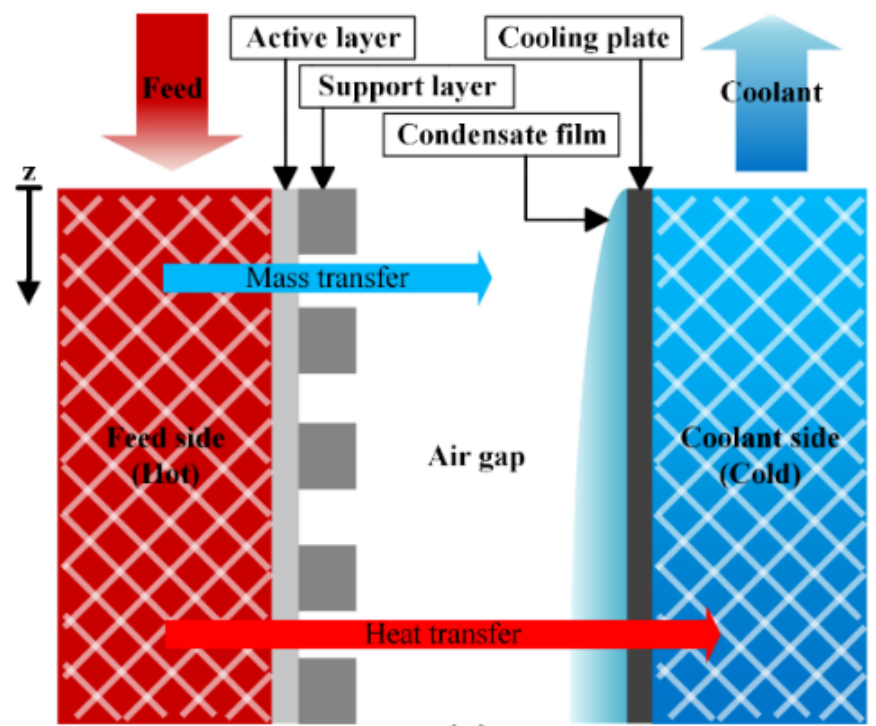

(a)

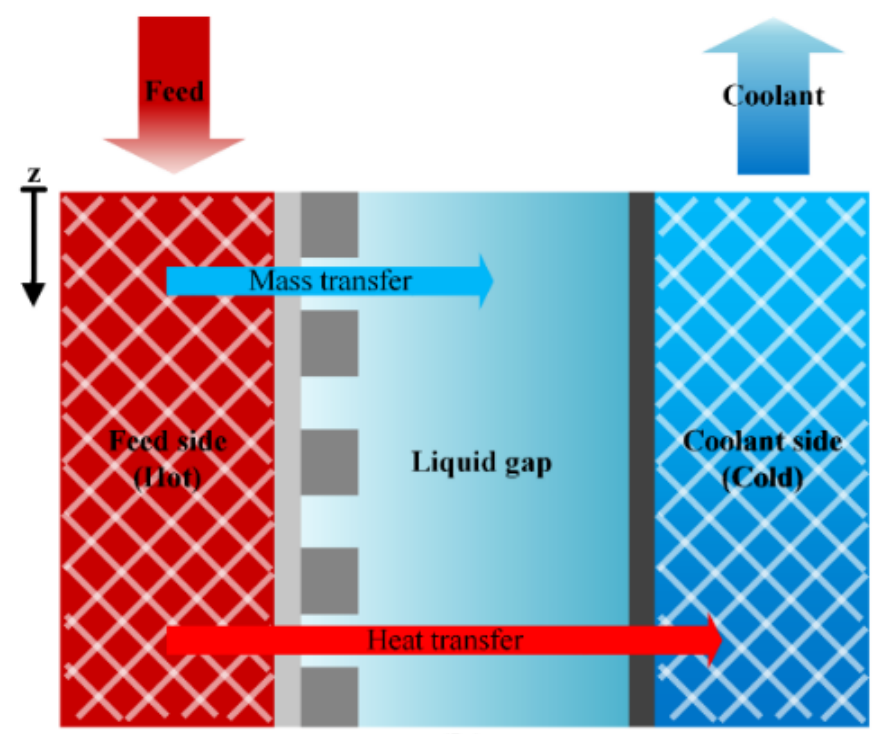

(b)

Fig. 1. Schematic diagram of the heat and mass transfer mechanisms in (a) AGMD and (b) LGMD. 

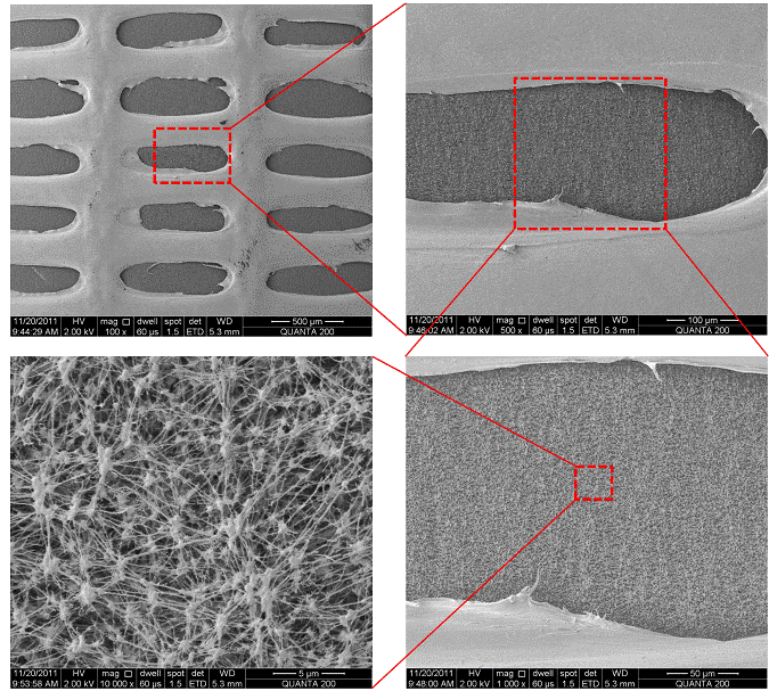

Fig. 2. SEM micrographs of a commercial PTFE/PP composite membrane. Clockwise from top left: 100x, 500x, $1,000 \times$ and 10,000x magnifications.

\subsection{Air-gap membrane distillation (AGMD)}

With the assumptions given above, the momentum, mass, species, and energy balances for the feed side can be expressed in terms of pressure $\left(P_{f}\right)$, velocity $\left(v_{f}\right)$, concentration $\left(x_{f}\right)$, and temperature $\left(T_{f}\right)[1,4,17]$. The momentum balance is obtained by solving the z-component of Navier-Stokes equation as follows:

$\frac{d P_{f}}{d z}=-\frac{3 \mu_{f}}{h_{c h}^{2}} v_{f}$

The overall molar balance and the molar species balance for the salt species yield Eqs. (2) and (3) in terms of velocity $\left(v_{f}\right)$ and concentration $\left(x_{f}\right)$, respectively, as follows:

$$
\begin{aligned}
& \frac{1}{X_{f}} \frac{d v_{f}}{d z}-\frac{v_{f}}{X_{f}^{2}}\left(\frac{M_{s}}{\rho_{s}}-\frac{M_{w}}{\rho_{w}}\right) \frac{d x_{f}}{d z}=-\frac{J}{M_{f} \varepsilon_{s p} h_{c h}} \\
& \frac{x_{f}}{X_{f}} \frac{d v_{f}}{d z}+\frac{v_{f} M_{w}}{\rho_{w} X_{f}^{2}} \frac{d x_{f}}{d z}=0
\end{aligned}
$$

The energy balance on the feed side yields the following equation on simplification:

$$
\frac{d \rho_{f} v_{f} c_{p, f} T_{f}}{d z}=-\frac{Q_{f}}{\varepsilon_{s p} h_{c h}}
$$

For the coolant flow, the momentum and energy balances can be expressed in terms of the pressure $\left(P_{c}\right)$ and temperature $\left(T_{c}\right)$, respectively, as follows [4]: 
$\frac{d P_{c}}{d z}=-\frac{3 \mu_{c}}{h_{c h}^{2}} v_{c}$

$\frac{d \rho_{c} v_{c} c_{p, c} T_{c}}{d z}=-\frac{Q_{c}}{\varepsilon_{s p} h_{c h}}$

\subsubsection{Heat transfer modeling}

Heat transfer in AGMD includes the heat transferred across the feed boundary layer $\left(Q_{f}\right)$, composite membrane $\left(Q_{m}\right)$, air gap $\left(Q_{a g}\right)$, condensate film $\left(Q_{c f}\right)$, cooling plate $\left(Q_{c p}\right)$, and coolant boundary layer $\left(Q_{c}\right)$, as shown in Fig. 3.

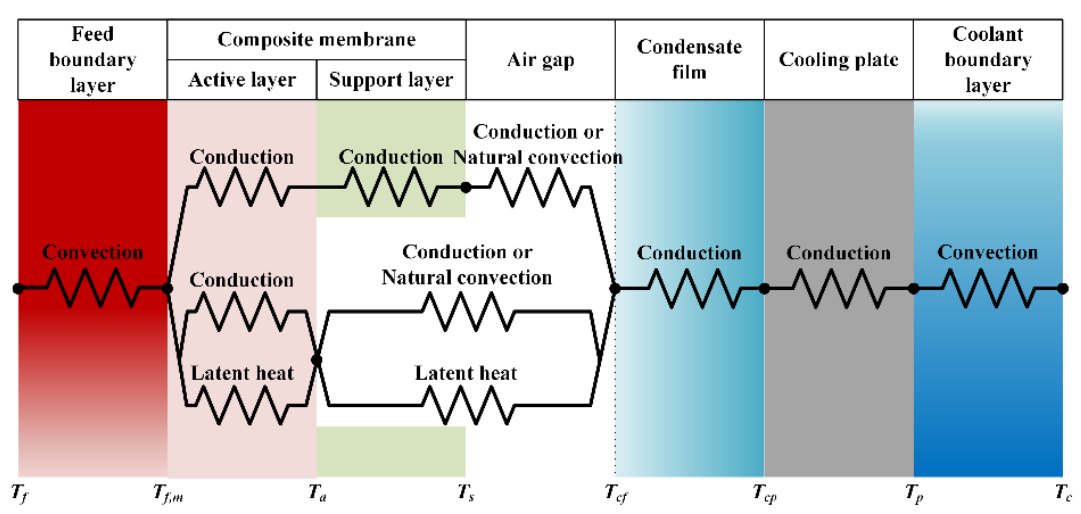

Fig. 3. Schematic of heat transfer through the composite membrane in AGMD.

The convective heat transfer across the feed boundary layer is written as follows $[4,16,18]$ :

$Q_{f}=h_{f}\left(T_{f}-T_{f, m}\right)$

where $T_{f}$ is the bulk feed temperature and $T_{f, m}$ is the interface temperature between the feed and membrane. As turbulence promoter and membrane supporter, a non-woven net spacer is used to enhance the heat and mass transfer in the feed channel. In order to incorporate an enhancement of heat and mass transfer by spacers, the spacer factor $\left(k_{d c}\right)$ is employed by considering the structural parameters of spacer, as given in Eqs. (9) and (10). Therefore, the convective heat transfer coefficient, $h_{f}$, in the spacer-filled feed channel can be determined by the modified Dittus-Boelter's correlation by incorporating the spacer factor on the flat surface of a fully-developed turbulent flow $[2,16,19-23]$.

$N u=\frac{h_{f} d_{h}}{k_{f}}=0.023 k_{d c} \operatorname{Re} e^{0.8} \operatorname{Pr}^{0.33}$ 


$$
\begin{aligned}
& k_{d c}=1.654\left(\frac{d_{s p f}}{h_{s t}}\right)^{-0.039} \varepsilon_{s p}^{0.75}\left[\sin \left(\frac{\theta}{2}\right)\right]^{0.086} \\
& \varepsilon_{s p}=1-\frac{\pi d_{s p f}^{2}}{2 l_{m} \delta_{s p} \sin \theta}
\end{aligned}
$$

Here, $k_{f}$ is the thermal conductivity of the feed solution, $N u$ is the Nusselt number, $d_{h}$ is the hydraulic diameter, defined as $4 \varepsilon_{s p} /\left[2\left(w_{c h}+h_{c h}\right) / w_{c h} h_{c h}+4(1-\varepsilon) / d_{f}\right], R e$ is the Reynolds number, $\operatorname{Pr}$ is the Prandtl number, $d_{f}$ is the filament diameter of spacer, $\delta_{s p}$ is the spacer thickness, $\varepsilon_{s p}$ is the spacer porosity, $l_{m}$ is the mesh size, $\theta$ is the hydrodynamic angle, and $w_{c h}$ is the channel width.

The overall heat transfer through the composite membrane can be calculated as follows [12]:

$$
Q_{m}=Q_{m, a}+Q_{m, a-s}
$$

where $Q_{m, a}$ and $Q_{m, a-s}$ are the heat transfers across the active-only and active/support layers, respectively. Here, the heat transfer through the active/support layer consists only of conductive heat transfer, as the mass transfer across the active/support layer is negligible [12]. Therefore, the heat transfers can be described as follows:

$$
\begin{aligned}
& Q_{m, a}=J_{a g m d} \Delta H_{m, a}+\frac{\varepsilon_{s f}}{R_{m, a}}\left(T_{f, m}-T_{a}\right) \\
& Q_{m, a-s}=\frac{1-\varepsilon_{s f}}{R_{m, a-s}}\left(T_{f, m}-T_{s}\right)
\end{aligned}
$$

where $T_{a}$ and $T_{s}$ are the interface temperatures between the active layer and the air gap and between the support layer and the air gap, respectively, $J_{a g m d}$ is the mass flux, $\Delta H_{m, a}$ is the enthalpy of evaporation, and $\varepsilon_{s f}$ is the surface porosity, defined as the surface area of the PTFE active layer exposed to the permeate side divided by the total membrane surface area. The thermal resistance, $R_{m}$, in Eqs. (12) and (13) can be described as follows [12]:

$$
\begin{aligned}
& R_{m, a}=\frac{\delta_{a}}{k_{m, a}} \\
& R_{m, a-s}=\left(\frac{\delta_{a}}{k_{m, a}}+\frac{\delta_{s}}{k_{m, s}}\right)
\end{aligned}
$$

where $k_{m, i}=\varepsilon_{m, i} k_{a i r}+\left(1-\varepsilon_{m, i}\right) k_{i}, i=a, s . k_{m, i}$ is the effective thermal conductivity of the composite membrane [12], $k_{\text {air }}$ is the thermal conductivity of air in the pores, and $k_{i}$ is the thermal conductivity of the membrane material. 
The heat transfers across the air gap are estimated as follows:

$Q_{a g, a}=J_{a g m d} \Delta H_{a g, a}+\varepsilon_{s f} h_{a g}\left(T_{a}-T_{c f}\right)$

$Q_{a g, a-s}=\left(1-\varepsilon_{s f}\right) h_{a g}\left(T_{s}-T_{c f}\right)$

where $T_{c f}$ is the interface temperature between the air gap and the condensate film and the heat transfer coefficient across the air gap, $h_{a g}$, is expressed as follows:

$h_{a g}=\frac{k_{a g} N u}{\delta_{a g}}$

where $N u$ can be calculated by considering natural convection, Eq. (19), or conduction, Eq. (20), depending on the geometry, configuration, material, and operating conditions as follows:

$N u=0.197 R a_{L}^{1 / 4}\left(\frac{L}{\delta_{a g}}\right)^{-1 / 9}, \begin{gathered}11<L / \delta_{a g}<42 \\ 0.5<\operatorname{Pr}<2 \\ 2 \times 10^{3} \leq R a_{L}<2 \times 10^{5}\end{gathered}$

$N u=1$ (pure conduction), $R a_{L}<2 \times 10^{3}$

with $R a_{L}=\frac{g \beta\left(T_{s}-T_{c f}\right) \delta_{a g}^{3}}{v^{2}} \operatorname{Pr}$

In the above equations, $R a_{L}$ is the Rayleigh number, $g$ is the gravitational constant, $\beta$ is the volume expansion coefficient, $v$ is the kinematic viscosity, and $L$ is the channel length.

Thus, the overall heat transfer through the air gap is given as shown below.

$Q_{a g}=Q_{a g, a}+Q_{a g, a-s}$

Also, the heat transfer across the condensate film is determined by the following equation $[4,13,16,24]$ :

$Q_{c f}=h_{c f}\left(T_{c f}-T_{c p}\right)$

where $T_{c p}$ is the interface temperature between the condensate film and the cooling plate, and the heat transfer coefficient $h_{c f}$ can be calculated as follows [25-27].

$h_{c f}=0.943\left(\frac{g \rho_{c f}^{2} \Delta H k_{c f}^{3}}{L \mu_{c f}\left(T_{c f}-T_{c p}\right)}\right)^{1 / 4}$

The heat transfer through the cooling plate is given by the equation shown below $[4,13,16,24]$ :

$Q_{c p}=\frac{k_{c p}}{\delta_{c p}}\left(T_{c p}-T_{p}\right)$ 
where $T_{p}$ is the interface temperature between the cooling plate and the coolant, $k_{c p}$ is the thermal conductivity of cooling plate material, and $\delta_{c p}$ is the thickness of the cooling plate.

The heat transfer across the coolant boundary layer is expressed as follows $[4,13,16,24]$ :

$Q_{c}=h_{c}\left(T_{p}-T_{c}\right)$

where $T_{c}$ is the coolant temperature and $h_{c}$ is the heat transfer coefficient at the spacer-filled coolant channel, which is same as that defined in Eq. (8) at the spacer-filled feed channel.

The overall heat transfer in the AGMD process at steady state can be established as follows [4].

$Q_{f}=Q_{m}=Q_{a g}=Q_{c f}=Q_{c p}=Q_{c}$

$Q_{m, a}=Q_{a g, a}, \quad Q_{m, a-s}=Q_{a g, a-s}$

\subsubsection{Mass transfer modeling}

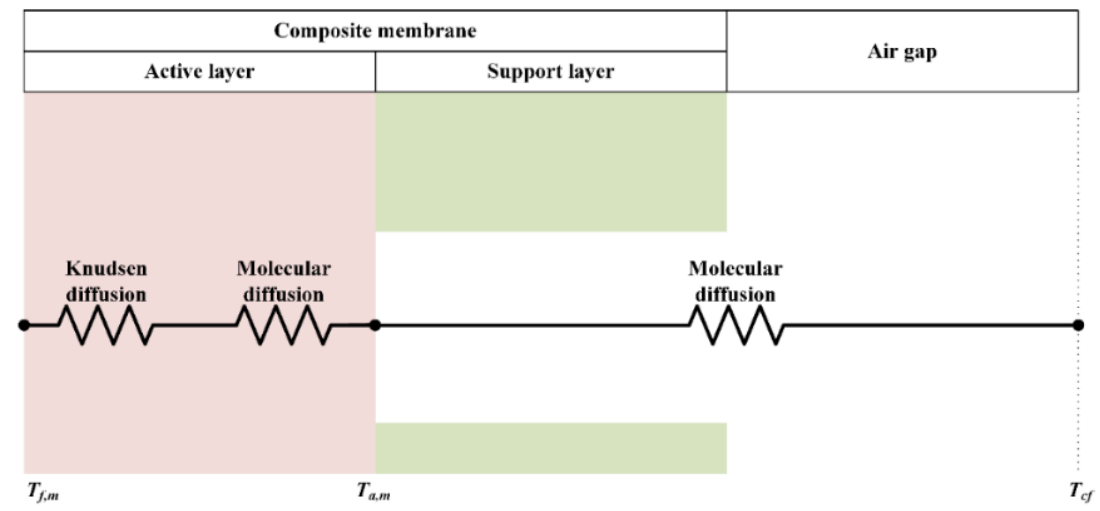

Fig. 4. Schematic of mass transfer through the composite membrane in AGMD.

The permeate flux across the composite membrane is expressed as follows.

$J_{a}=\varepsilon_{s f} C_{a}\left(P_{f, m}-P_{a}\right)$

As shown in Fig. 4, the relevant transport mechanisms for water vapor in AGMD are Knudsen diffusion and molecular diffusion. The membrane distillation coefficient through the active-only layer can be estimated by the equation below $[16,18]$ :

$C_{a}=\left(\frac{1}{C_{k n}}+\frac{1}{C_{m o l}}\right)^{-1}$

where $C_{k n}$ is the Knudsen diffusion coefficient and $C_{m o l}$ is the molecular diffusion coefficient. The equations for 
these coefficients are given as follows $[4,16,18]$ :

$$
\begin{aligned}
C_{k n} & =\frac{4}{3} \frac{d_{p} \varepsilon_{a}}{\delta_{a} \tau_{a}} \sqrt{\frac{M_{w}}{2 \pi R T}} \\
C_{m o l} & =\frac{M_{w}}{\left(P-P_{v}\right)} \frac{\varepsilon_{a} D P}{\delta_{a} \tau_{a} R T}
\end{aligned}
$$

where $\varepsilon_{a}$ is the active layer membrane porosity, $D$ is the diffusion coefficient, $P$ is the total pressure, $d_{p}$ is the membrane pore diameter, $\tau_{a}$ is the active layer membrane tortuosity, $\delta_{a}$ is the active layer membrane thickness, and $R$ is the gas constant. The binary diffusion coefficient $D$ is calculated by the Fuller-Shelltler-Giddings (FSG) empirical equation expressed as follows [12]:

$D=1.19 \times 10^{-4}\left(\frac{T_{m}^{1.75}}{P_{m}}\right)$

where $T_{m}$ and $P_{m}$ are the mean temperature and mean water vapor pressure, defined as $T_{m}=\left(T_{f, m}+T_{a}\right) / 2$ and $P_{m}=\left(P_{f, m}+P_{a}\right) / 2$, respectively.

In Eq. (32), the water vapor pressure without dissolved species in the water can be calculated using the Antoine equation, as shown below.

$$
P_{v}=\exp \left(23.1964-\frac{3816.44}{T-46.13}\right)
$$

Due to the existence of dissolved species with molar concentrations at the feed side, the reduction of the vapor pressure can be determined using Raoult's law by assuming as an ideal solution for simplicity $[4,12,28]$ :

$$
P_{f, m}=P_{v}\left(1-x_{f, s}\right)
$$

where $x_{f, s}$ is the molar fraction of the solution and $P_{v}$ is the water vapor pressure calculated by Eq. (34).

Also, the mass flux across the air gap is written as follows $[4,18,29]$ :

$$
J_{a g}=C_{a g}\left(P_{a}-P_{c f}\right)
$$

where $P_{a}$ is the interface pressure between the active layer and the air gap and $P_{c f}$ is the interface pressure between the air gap and the condensate film.

For the stagnant non-condensable gases trapped within the membrane pores and in the air gap between the membrane and the condensing plate, the dominant transport mechanism is molecular diffusion expressed as follows $[4,18,29]$. 
$C_{a g}=\frac{M_{w}}{\left(P-P_{v}\right)} \frac{D P}{\delta_{a g} R T}$

Both the permeate fluxes across the active-only layer $\left(J_{a}\right)$ and the air gap $\left(J_{a g}\right)$ are assumed to be the same and can be expressed as follows $[4,16,18]$.

$J_{\text {agmd }}=J_{a}=J_{a g}$

Based on Eq. (38), Eqs. (29) and (36) can be rearranged, respectively, as follows.

$\frac{J_{a g m d}}{\varepsilon_{s f} C_{a}}=\frac{J_{a}}{\varepsilon_{s f} C_{a}}=P_{f, m}-P_{a}, \quad \frac{J_{a g m d}}{C_{a g}}=\frac{J_{a g}}{C_{a g}}=P_{a}-P_{c f}$

Combining the above equations yields the local permeate flux as follows.

$J_{\text {agmd }}=\left(\frac{1}{\varepsilon_{s f} C_{a}}+\frac{1}{C_{a g}}\right)^{-1}\left(P_{f, m}-P_{c f}\right)$

The mean permeate flux over the membrane length $L$ is given by the following equation $[1,12,30]$.

$J_{m}=\frac{1}{L} \int_{0}^{L} J_{\text {agmd }} d z$

\subsection{Liquid-gap membrane distillation (LGMD)}

Theoretical models of LGMD are similar to those of AGMD described in the previous section. In particular, the momentum, mass, and energy balance equations for the bulk feed and coolant flows in LGMD are the same as those of AGMD, as defined in Eqs. (1)-(6). The main differences compared to AGMD models are the heat and mass transfers through the composite membrane and the liquid gap, while the transport mechanisms for the feed, condensate plate, and coolant are the same.

\subsubsection{Heat transfer modeling}

Fig. 5 illustrates the heat transfer mechanism in LGMD, which includes heat transferred across the feed boundary layer $\left(Q_{f}\right)$, composite membrane $\left(Q_{m}\right)$, liquid gap $\left(Q_{l g}\right)$, condensate plate $\left(Q_{c p}\right)$, and coolant $\left(Q_{c}\right)$. In this section, the heat transfers through the feed, condensate plate, and coolant are not described, as these are the same as those of AGMD expressed in Eqs. (7), (25), and (26), respectively. 


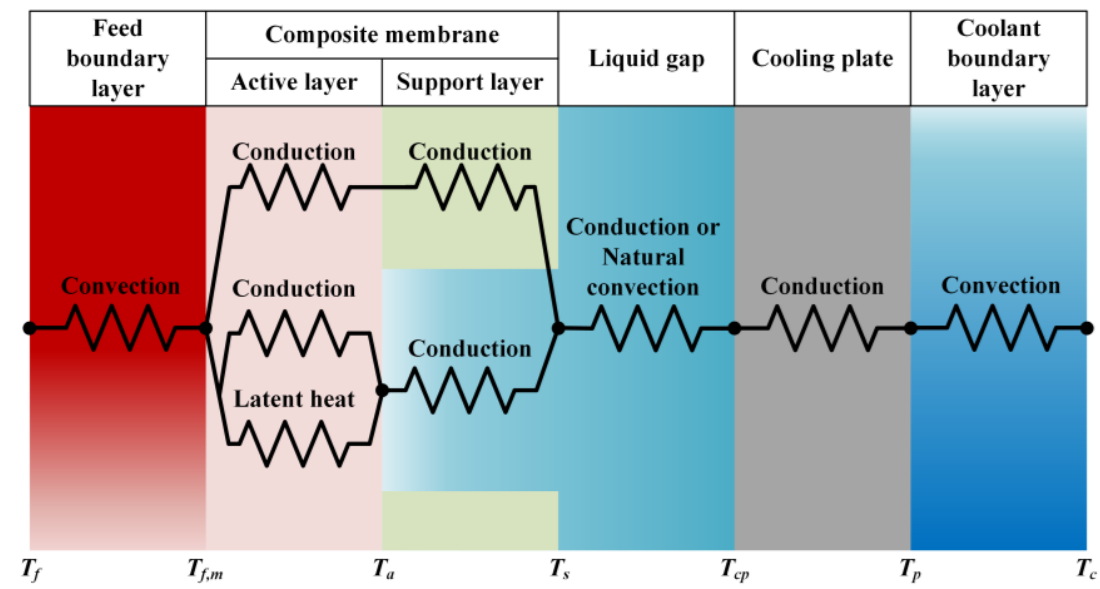

Fig. 5. Schematic of heat transfer through the composite membrane in LGMD.

The heat transfer through the composite membrane consisting of active-only and active/support layers can be described as follows [1,12]:

$$
\begin{aligned}
& Q_{m, a}=J_{\text {lgmd }} \Delta H_{a}+\frac{\varepsilon_{s f}}{R_{m, a}}\left(T_{f, m}-T_{a}\right) \\
& Q_{m, a-s}=\frac{1-\varepsilon_{s f}}{R_{m, a-s}}\left(T_{f, m}-T_{s}\right)
\end{aligned}
$$

where $Q_{m, a}$ and $Q_{m, a-s}$ are the heat transfers across the active-only and active/support layers, respectively. Here, $R_{m, a}$ and $R_{m, a-s}$ are calculated using Eqs. (14) and (15), respectively. The total heat transfer is then given as follows [12].

$Q_{m}=Q_{m, a}+Q_{m, a-s}$

Additionally, in order to determine $T_{a}$ in Eq. (42), the conductive heat transfer is considered as follows [12].

$Q_{s}=\left(\frac{k_{w}}{\delta_{s}}\right)\left(T_{a}-T_{s}\right)$

The heat flux across the liquid gap is written as follows [31].

$Q_{l g}=h_{l g}\left(T_{s}-T_{c p}\right)$

The heat transfer coefficient, $h_{l g}$, inside the gap filled with a liquid can be shown as follows:

$$
h_{l g}=\frac{k_{l g} N u}{\delta_{l g}}
$$

where $N u$ can be obtained by considering natural convection or conduction, respectively, as follows $[14,32,33]$ : 


$$
N u=0.046 R a_{L}^{1 / 3}, \quad \begin{gathered}
1<L / \delta_{l g}<40 \\
10^{6} \leq \operatorname{Rr} a_{L}<10^{9}
\end{gathered}
$$

$N u=1$ (pure conduction), $\quad R a_{L}<2 \times 10^{3}$

The convective heat transfer coefficient in the range of $2 \times 10^{3} \leq R a_{L}<10^{6}$ is estimated by a linear interpolation between Eqs. (48) and (49).

The overall heat transfer through the LGMD process at steady state can be established as follows:

$Q=Q_{f}=Q_{m}=Q_{l g}=Q_{c p}=Q_{c}$

$Q_{m, a}=Q_{s}$

\subsubsection{Mass transfer modeling}

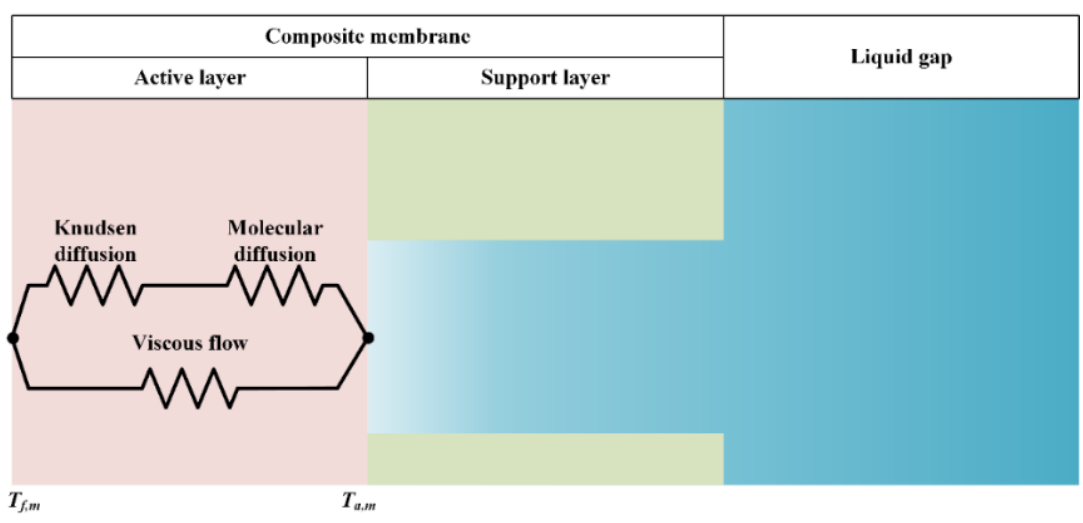

Fig. 6. Schematic of mass transfer through the composite membrane in LGMD.

The mass transfer of LGMD through the membrane has transport mechanisms such as Knudsen diffusion, molecular diffusion, and viscous flow, as shown in Fig. 6. This phenomenon is the same as the mass transfer of DCMD. The permeate flux through the composite membrane can be calculated as shown below [12].

$$
J_{\text {lgmd }}=\varepsilon_{s f} C_{l g}\left(P_{f, m}-P_{a}\right)
$$

The membrane distillation coefficient for the active layer is calculated using the following equation [12,34]:

$$
C_{l g}=\left(\frac{1}{C_{k n}}+\frac{1}{C_{m o l}}\right)^{-1}+C_{p f}
$$

where $C_{k n}$ and $C_{m o l}$ are equal to the values calculated using Eqs. (31) and (32), respectively. $C_{p f}$ is the viscous flow coefficient $[2,12,34]$, as shown below: 
$C_{p f}=\frac{M_{w}}{8 \mu} \frac{\varepsilon_{a}}{\tau_{a} \delta_{a}} \frac{r_{p}^{2} P_{v}}{R T}$

where $r_{p}$ is the membrane pore radius and $\mu$ is the dynamic viscosity of water vapor.

\subsection{Solution procedure}

In both the AGMD and LGMD processes shown in Fig. 1, the bulk feed and coolant streams are circulated in a countercurrent-flow manner. Thus, the velocities, concentrations, and temperatures are known at the inlets of the feed and coolant solutions (i.e., $z=0$ and $L$, respectively), while the pressures are known at their outlets (i.e., $z=L$ and 0 , respectively). For the simulations, the boundary conditions for the velocity, pressure, concentration, and temperature at the bulk feed side are as follows:

$v_{f}(0)=v_{f, i n}=\frac{V_{f, i n}}{\varepsilon_{s p} h_{c h} w_{c h}}, P_{f}(L)=P_{0}, \quad x_{f}(0)=x_{f, i n}, T_{f}(0)=T_{f, i n}$

where $P_{0}$ depicts the ambient atmospheric pressure at the outlets of the feed and coolant channels, and the subscript in depicts the inlets of the feed and coolant channels.

On the other hand, the boundary conditions for the velocity, pressure, and temperature at the coolant side are as follows:

$v_{c}(L)=v_{c, i n}=\frac{V_{c, i n}}{\varepsilon_{s p} h_{c h} w_{c h}}, \quad P_{c}(0)=P_{0}, T_{c}(L)=T_{c, i n}$

In this study, the thermophysical properties of water and seawater were employed from [35]. The set of coupled ordinary differential equations (ODEs) of the AGMD and LGMD processes, i.e., Eqs. (1)-(6), including both bulk feed and coolant flows and the characteristics of the membrane for heat and mass transfer, were solved simultaneously with the boundary conditions given in Eqs. (55) and (56). The unknowns (i.e., $P_{f}(0), v_{c}$ $(0)$, and $T_{c}(0)$ at $\left.z=0\right)$ are guessed, which converts the boundary-value problem into an initial-value problem. In this study, Broyden's method, which is a quasi-Newton method for finding solutions of nonlinear equations, was employed to solve the system of ODEs $[1,12,17,37,38]$. The solution for each control volume proceeds forward until $z=L$, and then the presumed values are updated. Thus, this procedure is iterated until the boundary conditions, Eqs. (55) and (56), are satisfied with an absolute error below $10^{-6}$.

\section{Results and discussion}

\subsection{Validation of the numerical model}




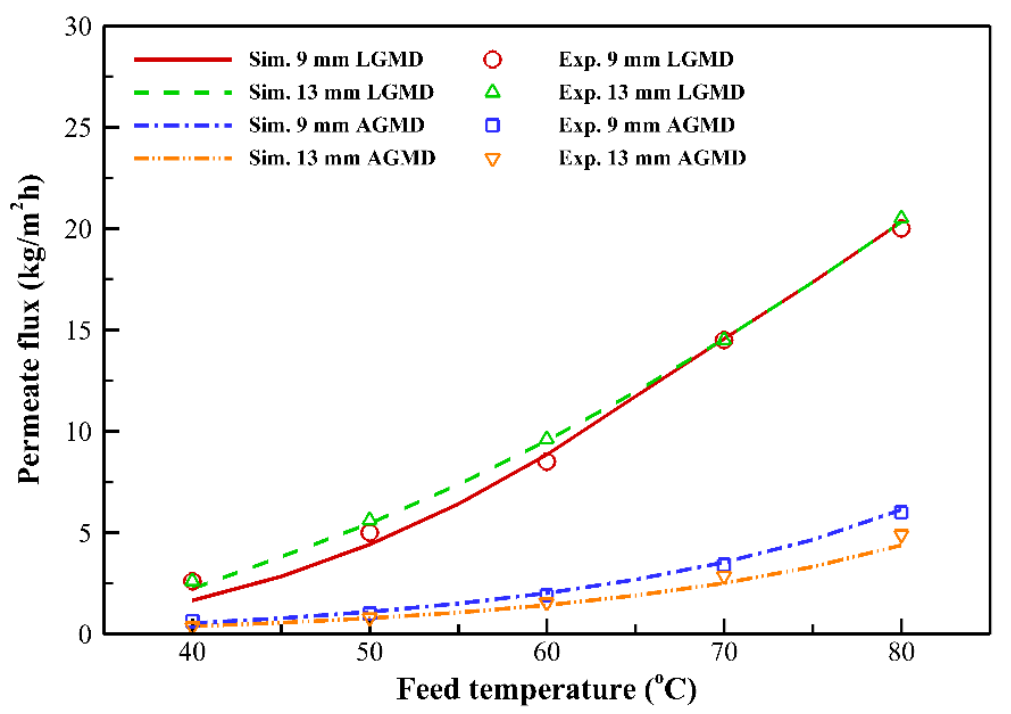

Fig. 7. Experimental (symbol) $[14,16]$ and simulated (line) permeate fluxes in AGMD and LGMD with different gap sizes $\left(\delta_{g a p}=9,13 \mathrm{~mm}\right)$ at $T_{f}=40-80^{\circ} \mathrm{C}, T_{c}=20^{\circ} \mathrm{C}$, and $V_{f}=V_{c}=1.5 \mathrm{l} / \mathrm{min}$

The numerical models developed for the AGMD and LGMD processes were evaluated for inlet feed temperatures in the range of $40{ }^{\circ} \mathrm{C}$ to $80^{\circ} \mathrm{C}$ while maintaining a constant coolant temperature and inlet feed and coolant flow rates of $20^{\circ} \mathrm{C}$ and $1.5 \mathrm{l} / \mathrm{min}$, respectively. The feed salt concentration was kept constant at $4.2 \mathrm{wt} \%$. Fig. 7 shows the comparison of the experimental and predicted results of the permeate flux. All the experiments were repeated to demonstrate the reproducibility of permeate fluxes measured at different feed water temperatures, and the maximum deviations in the measured permeate fluxes were found to be less than $6 \%$ for LGMD and $2 \%$ for AGMD, respectively $[14,16]$. It was shown that both the predicted and measured permeate fluxes increased exponentially as the feed temperature increased. The model predictions were in good agreement with the experimental results over the entire temperature range, with a maximum relative deviation of $10 \%$.

\subsection{Parametric analysis of AGMD and LGMD}

Tables 1 and 2 show the specifications and characteristics of the spacer and composite membrane employed in the present work, respectively. The surface porosity was confirmed to be $42 \%$ using CAD software based on the Fig. 2. The membrane module specifications are listed in Table 3. The numerical model was assessed at various operating conditions including the temperatures and flow rates of the feed and coolant streams and the membrane surface porosity. Here, the feed salt concentration was assumed to be $4.2 \mathrm{wt} \%$. 
Table 1 Specifications of the spacer.

\begin{tabular}{lc}
\hline Material & PP \\
\hline Spacer thickness, $\delta_{s p}(\mathrm{~mm})$ & 0.8 \\
Filament diameter, $d_{s p f}(\mathrm{~mm})$ & 0.4 \\
Angle between filaments, $\theta(\mathrm{deg})$ & 90 \\
Mesh size, $l_{m}(\mathrm{~mm})$ & 2 \\
\hline
\end{tabular}

Table 2 Characteristics of the PTFE/PP composite membrane.

\begin{tabular}{lll}
\hline Material & PTFE & PP \\
\hline Thickness, $\delta(\mu \mathrm{m})$ & 20 & 80 \\
Porosity, $\varepsilon(\%)$ & 70 & 34 \\
Mean pore size, $r_{p}(\mu \mathrm{m})$ & 0.5 & 0.1 \\
Liquid entry pressure, $L E P_{w}(\mathrm{kPa})$ & 207 & 160
\end{tabular}

Table 3 Specifications of the membrane module.

\begin{tabular}{ll}
\hline Channel height, $h_{c h}(\mathrm{~m})$ & 0.002 \\
Channel width, $w_{c h}(\mathrm{~m})$ & 0.05 \\
Channel length, $L(\mathrm{~m})$ & 0.1 \\
Air/liquid gap thickness, $\delta(\mathrm{mm})$ & $1-13$ \\
\hline
\end{tabular}

\subsubsection{Effect of the feed temperature and flow rate}

The results in Fig. 8 imply that the permeate flux increases with increasing feed temperature at a coolant temperature of $25{ }^{\circ} \mathrm{C}$ for both AGMD and LGMD processes. A significant augmentation of the MD permeate flux was achieved at the higher feed temperatures because of the enhanced transmembrane temperature difference, i.e., MD driving force, as demonstrated previously [14,15,36]. In the AGMD processes considered in this study, the Nusselt number $(\mathrm{Nu})$ is always unity as the Rayleigh number $(R a)$ calculated by Eq. (21) is less than $2 \times 10^{3}$. As a result, only conduction heat transfer will occur in the air gap, and based on Fourier's law of heat conduction, the larger the air gap thickness, the higher the heat transfer resistance. Therefore, the heat loss through the air gap in the AGMD process can be ignored, mainly due to the very low thermal conductivity of air. 
Meanwhile, the AGMD permeate flux decreases greatly with increasing air gap thickness, which is attributed to increased diffusion resistance through the air gap [13,24,25,27]. It is also shown that the LGMD permeate fluxes are significantly higher than those of AGMD at a given gap size, regardless of the feed temperature. This is due to the nonexistence of additional diffusion resistance through the air gap and the higher transmembrane temperature difference in LGMD. Similar to the trends of the AGMD permeate flux, as the liquid-gap size increases from $1 \mathrm{~mm}$ to 5 or $7 \mathrm{~mm}$, the LGMD permeate flux also decreases over the entire temperature range. However, the further increase of liquid gap results in an asymptotic increase of the permeate flux. This phenomenon occurs primarily due to the enhancement of natural convection, which results in a relatively higher heat transfer across the boundary layer in the liquid gap leading to lower temperature polarization and thus, a higher transmembrane temperature difference. In addition, at a fully-developed turbulent natural convection regime $\left(R a \geq 10^{6}\right)$ with a higher liquid-gap size, variations in the permeate flux tend to be negligible because the influence of gap size on the permeate flux diminishes as $R a$ number increases $[37,38]$. These results agree well with the experimental results [14] illustrated in Fig. 7, showing that the larger the liquid-gap size, the slightly higher the permeate flux, but at higher feed temperatures above $70{ }^{\circ} \mathrm{C}$ the variance in the permeate flux is nearly negligible.

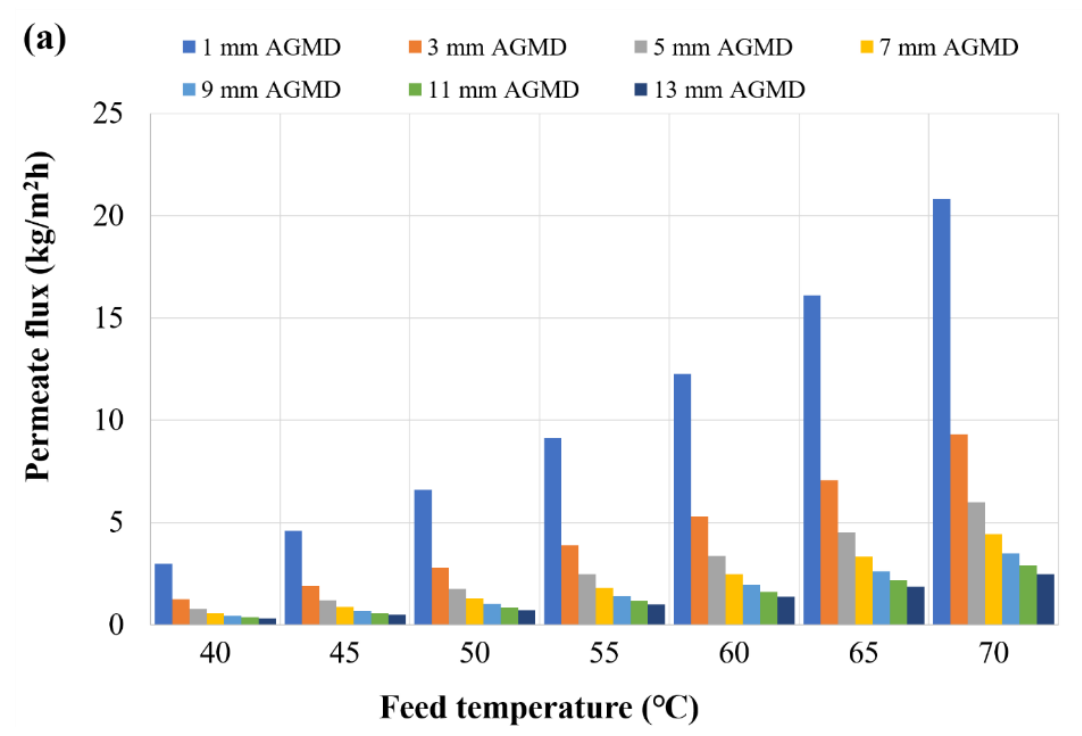




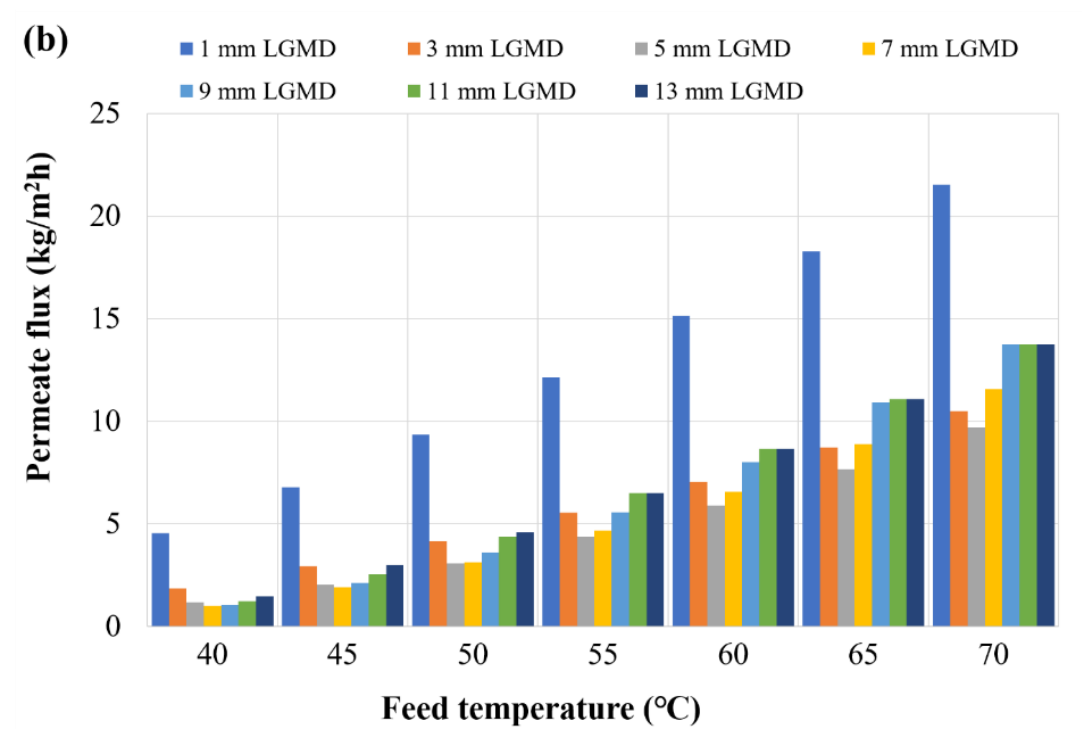

Fig. 8. Effect of the feed temperature $\left(T_{f}\right)$ in the range of $40-70{ }^{\circ} \mathrm{C}$ on (a) AGMD and (b) LGMD permeate fluxes at $V_{f}=2.5 \mathrm{l} / \mathrm{min}, V_{c}=1.5 \mathrm{l} / \mathrm{min}, T_{c}=25^{\circ} \mathrm{C}$, and $\varepsilon_{s}=0.42$.

Fig. 9 illustrates the effect of the feed flow rate ranging from $0.51 / \mathrm{min}$ to $5.01 / \mathrm{min}$ on the permeate flux of both AGMD and LGMD with an inlet feed temperature of $70{ }^{\circ} \mathrm{C}$, while keeping the other operating conditions constant, as before. It is shown that the LGMD permeate fluxes are always greater than those of AGMD and both MD permeate fluxes increase asymptotically with increasing feed flow rate, especially for all of the LGMDs and AGMD with a $1 \mathrm{~mm}$ air-gap size. At lower feed flow rates, the boundary layer resistance on the feed side is representative of the overall mass transfer resistance and thus, the permeate flux was largely enhanced with increasing flow rate. This behavior can be attributed to the heat transfer augmentation through the feed stream, resulting in a decrease of the temperature gradient across the feed-side boundary layer yet lower temperature polarization [1,39-41]. However, a further increase of the feed flow rate leads to a plateau in the MD permeate flux profile as the overall mass transfer resistance is dominated by the diffusion (or heat transfer) resistance in the air (or liquid) gap [42]. As the flow rate increases at the air and liquid gaps of $1 \mathrm{~mm}$, the mass transfer resistances in the gaps increase from $50 \%$ to $65 \%$ and from $46 \%$ to $77 \%$, respectively, of the total mass transfer resistance, whereas those across the feed-side boundary layers decrease from $30 \%$ to $9 \%$ and from $46 \%$ to $12 \%$, respectively. Meanwhile, at higher air-gap sizes $(\geq 3 \mathrm{~mm})$, the diffusion resistance in the air gap highly limits the mass transfer for the AGMD process and thus, the effect of the feed flow rate on the permeate flux is negligibly small. 

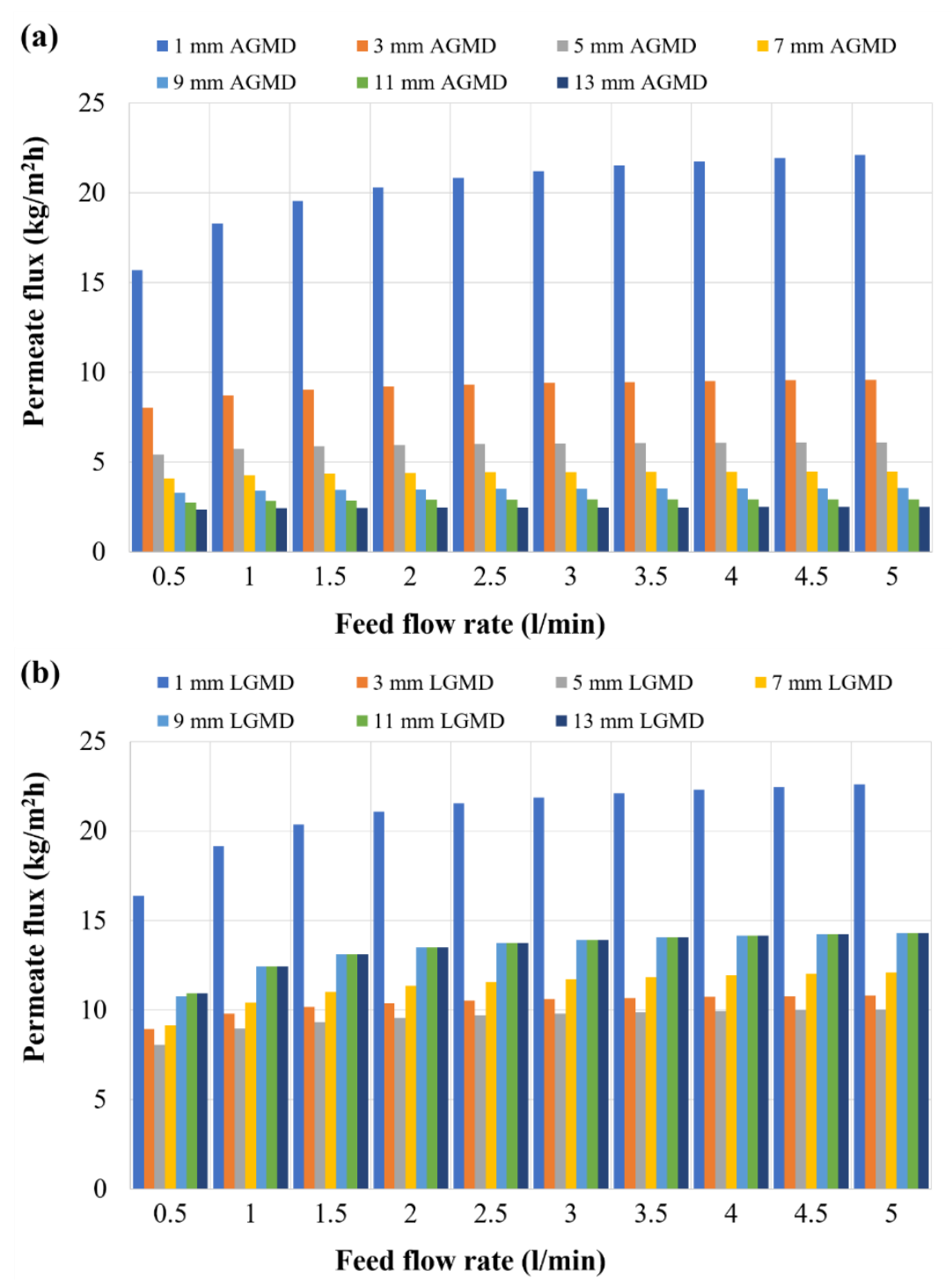

Fig. 9. Effect of the feed flow rate $\left(V_{f}\right)$ in the range of $0.5-5.01 / \mathrm{min}$ on (a) AGMD and (b) LGMD permeate fluxes at $V_{p}=1.5 \mathrm{l} / \mathrm{min}, T_{f}=70^{\circ} \mathrm{C}, T_{c}=25^{\circ} \mathrm{C}$, and $\varepsilon_{s}=0.42$.

\subsubsection{Effect of the coolant temperature and flow rate}

The influence of coolant temperature in the range of $10-30{ }^{\circ} \mathrm{C}$ on both AGMD and LGMD permeate fluxes while the other operating conditions mentioned previously were fixed is presented in Fig. 10. It is observed that as the coolant temperature increases, the LGMD permeate flux decreases greatly as compared to that of AGMD. This is because the interface temperature between the active layer and liquid gap, $T_{a}$, increases proportionally with the coolant temperature due to the higher heat transfer through the liquid gap compared to the AGMD case, resulting in a deterioration of the transmembrane driving force obtained from Eq. (52). In the AGMD process, on the other hand, the permeate flux is not influenced by the coolant temperature because the heat and mass transfer 
resistances in the air gap are predominant yet the interface pressure between the air gap and condensate film, $P_{c f}$, calculated by Eq. (34) is not sensitive in the low temperature range from $10{ }^{\circ} \mathrm{C}$ to $30^{\circ} \mathrm{C}$.
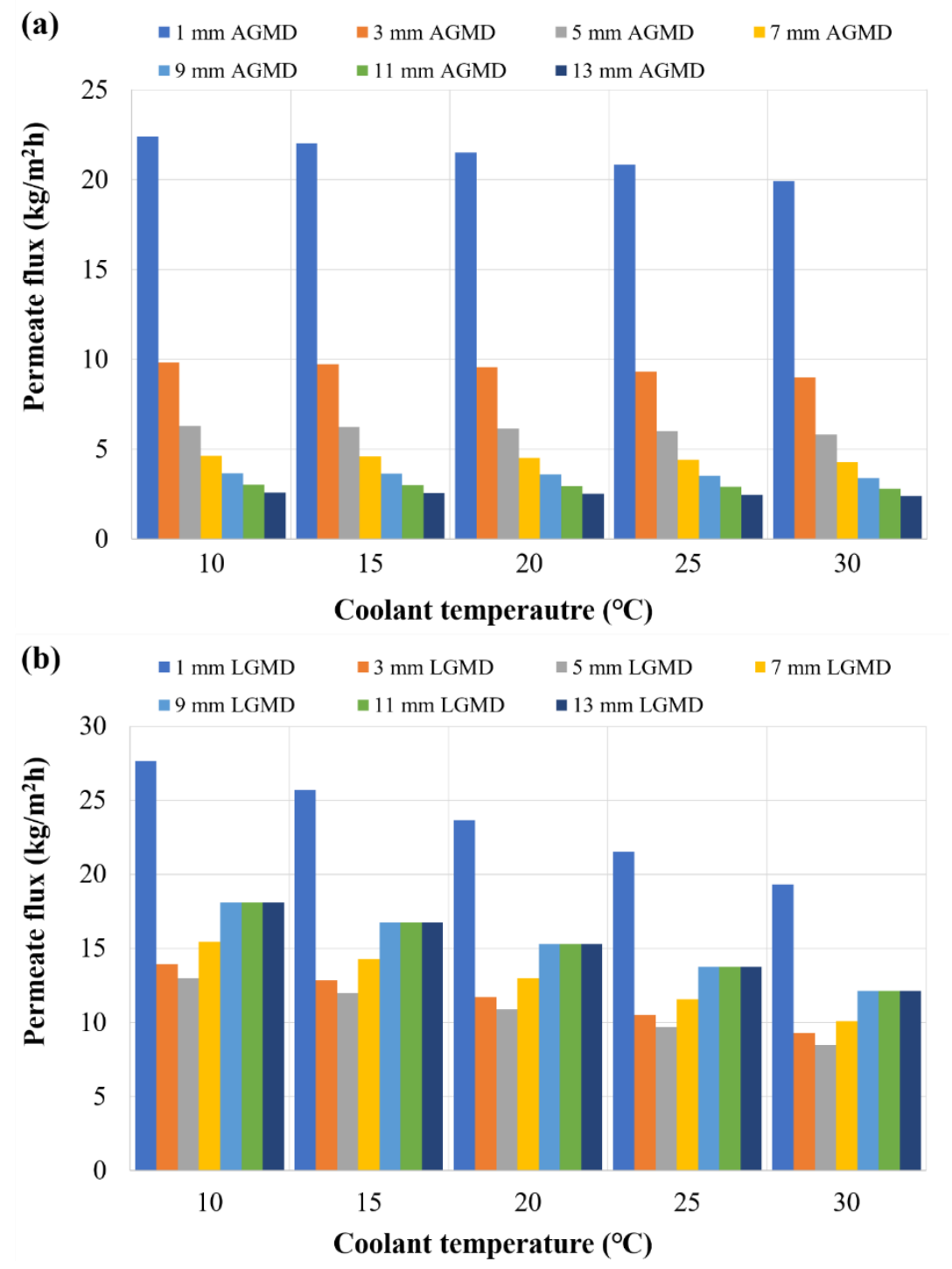

Fig. 10. Effect of the coolant temperature $\left(T_{c}\right)$ in the range of $10-30{ }^{\circ} \mathrm{C}$ on (a) AGMD and (b) LGMD permeate fluxes at $V_{f}=2.51 / \mathrm{min}, V_{c}=1.51 / \mathrm{min}, T_{f}=70^{\circ} \mathrm{C}$, and $\varepsilon_{s f}=0.42$.

Fig. 11 depicts the permeate fluxes of the AGMD and LGMD processes at different coolant flow rates. In general, at a given coolant temperature, a sufficient cooling energy should be supplied to remove the latent heat of condensation of the permeate vapor in both processes. It should be noted that a further supply of coolant to both membrane modules can lead to a higher pumping power as a consequence of the higher pressure drop. However, insufficient cooling and enhanced heat transfer resistance through the coolant-side boundary layer, 
induced by a low coolant flow rate, may cause an increase of the interface temperatures between the air gap and condensate film $\left(T_{c f}\right)$ and between the active layer and liquid gap $\left(T_{a}\right)$, respectively, for both the AGMD and LGMD processes. Hence, the permeate flux will decrease. Above all, the most dominant factor in the permeate fluxes of both AGMD and LGMD is the heat and mass transfer resistances through the air and liquid gaps. Therefore, as shown in Fig. 11, the permeate flux variation of the AGMD process with the high gap resistances is imperceptible to the coolant flow rate considered in this study whilst the LGMD permeate flux is dependent on the coolant flow rate, especially at lower coolant flow rates.
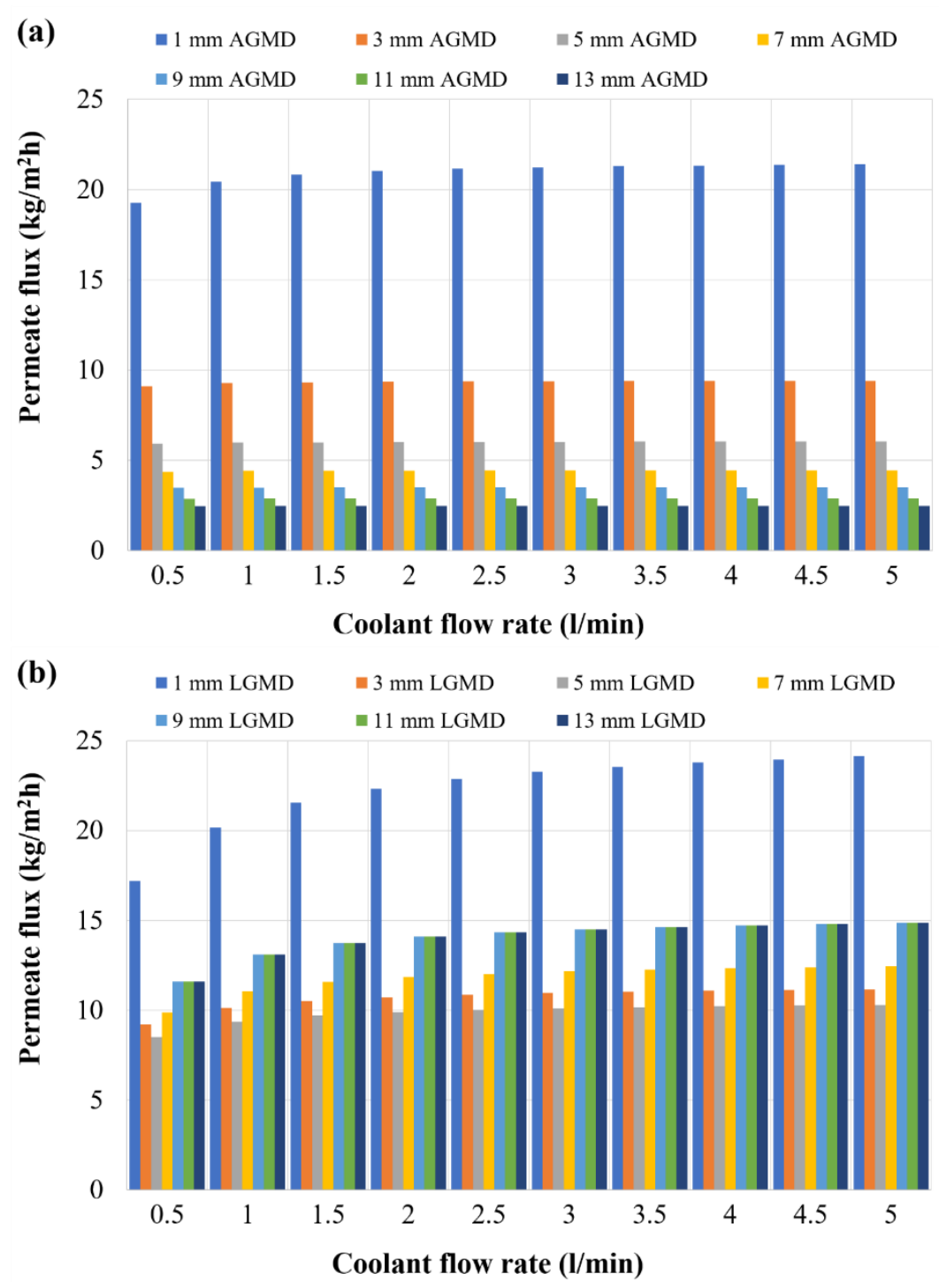

Fig. 11. Effect of the coolant flow rate $\left(V_{c}\right)$ in the range of $0.5-5.01 / \mathrm{min}$ on (a) AGMD and (b) LGMD permeate fluxes at $V_{f}=2.5 \mathrm{l} / \mathrm{min}, T_{f}=70^{\circ} \mathrm{C}, T_{c}=25^{\circ} \mathrm{C}$, and $\varepsilon_{s}=0.42$. 


\subsubsection{Effect of the membrane surface porosity}

Fig. 12 presents the permeate flux profiles with respect to the membrane surface porosity in the range of $0.1-$ 0.7. As shown in Eqs. (40) and (52), the membrane surface porosity $\left(\varepsilon_{s f}\right)$ is an important factor in determining the MD permeate flux. It was found that with an increase of the membrane surface porosity, the permeate fluxes increase asymptotically in both the AGMD and LGMD processes, which has already been demonstrated in the DCMD process [12]. At larger air-gap sizes ( $\geq 3 \mathrm{~mm}$ ), however, the higher mass transfer resistance through the air gap is significantly more dominant than that of the membrane and thus, the permeate flux variations are relatively insensitive even as the membrane surface porosity was increased [14,42]. In all cases of larger air-gap sizes, the air-gap mass transfer resistances account for more than about $66 \%$ of the total mass transfer resistance, while those across the membrane exhibit less than about $29 \%$. On the other hand, the mass transfer at a $1 \mathrm{~mm}$ air gap was significantly enhanced compared to that of larger air gaps, yet its magnitude becomes comparable to that of the membrane and hence, the AGMD permeate flux is significantly influenced by the membrane surface porosity. It is shown that as the surface porosity increases from 0.1 to 0.7 at the air gap of $1 \mathrm{~mm}$, the mass transfer resistances through the membrane decrease asymptotically from $51 \%$ to $13 \%$ of total mass transfer resistance, whereas those in the air gap increase asymptotically from $39 \%$ to $69 \%$.

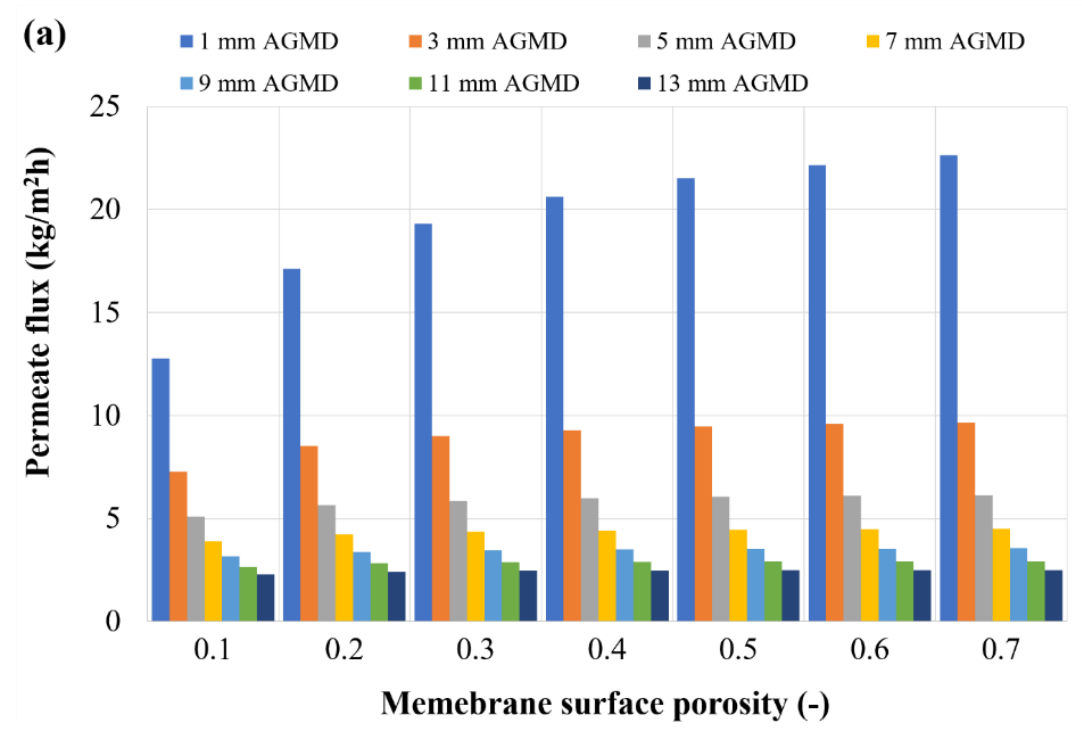




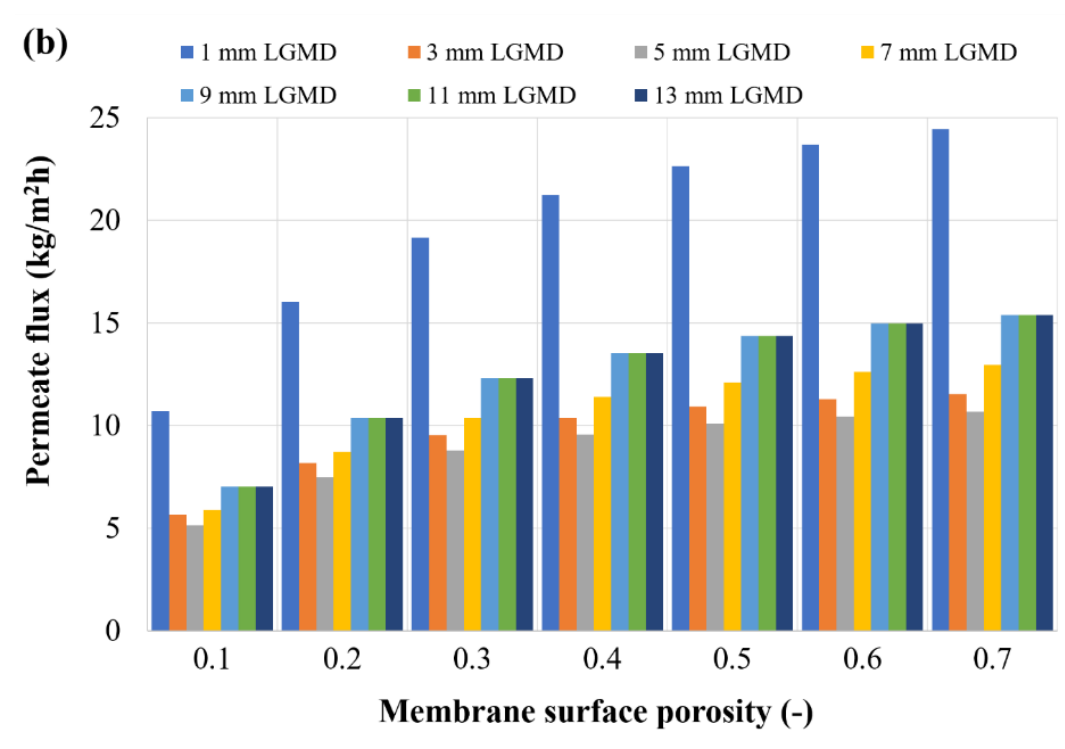

Fig. 12. Effect of the surface porosity $\left(\varepsilon_{s}\right)$ in the range of $0.1-0.7$ on (a) AGMD and (b) LGMD permeate fluxes at $V_{f}=2.5 \mathrm{l} / \mathrm{min}, V_{c}=1.5 \mathrm{l} / \mathrm{min}, T_{f}=70^{\circ} \mathrm{C}$, and $T_{c}=25^{\circ} \mathrm{C}$.

\section{Conclusions}

In the present work, rigorous theoretical models of AGMD and LGMD using a hydrophobic PTFE/PP composite membrane were developed. The developed models involve mass, momentum, species and energy balances in the feed and coolant streams, the mass and heat transfers through the membrane and air or liquid gap, and the physical characteristics of the composite membrane. The effects of the feed and coolant temperatures, the feed and coolant flow rates, and the membrane surface porosity on the MD performance were evaluated at different air- and liquid-gap sizes.

It was noted that as the liquid gap increased the LGMD permeate flux decreased exponentially up to its minimum at a certain liquid-gap size and then increased asymptotically. It was because the natural convection that brings about an improvement of heat and mass transfer occurred at a certain liquid gap, and then was enhanced with a further increase of the gap size. In general, the temperature polarization in the feed boundary layer diminishes with an increase of the feed flow rate, leading to an increased interface temperature between the feed and membrane and hence, the permeate flux. With larger air gaps, however, the AGMD permeate flux is restricted by the high diffusion resistance in the air gap. The AGMD permeate flux is less affected by the coolant temperature compared to the LGMD permeate flux. The negligible effect of the coolant temperature in AGMD is due to the low sensitivity of the interface pressure between the air gap and condensate film at the lower temperatures and also the heat and mass transfer resistances, which are strongly dominant in the air gap. The 
effect of the coolant flow rate was marginal on the AGMD permeate flux because of the heat and mass transfer resistances in the air gap, which are the most influential factors in the overall heat and mass transfers, although the heat transfer resistance through the coolant-side boundary layer decreases as the coolant flow rate increases. On the other hand, its effect on the LGMD permeate flux is relatively more significant at lower coolant flow rates. As compared to the mass transfer resistance at larger air gaps, its magnitude at a $1 \mathrm{~mm}$ air gap is comparable to that of the composite membrane. Therefore, the membrane surface porosity has a relatively large influence on the AGMD permeate flux at a $1 \mathrm{~mm}$ air gap.

In all cases of the AGMD process, the permeate flux exhibits a maximum at an air gap of $1 \mathrm{~mm}$. As expected, the larger permeate flux is achieved with a smaller air gap with lower mass transfer resistance. Similarly, the LGMD permeate flux at liquid gaps of less than $5 \mathrm{~mm}$ reveals a maximum at a gap of $1 \mathrm{~mm}$, whereas above 5 $\mathrm{mm}$ the permeate flux increases asymptotically, leading to a maximum at a gap size of about $9 \mathrm{~mm}$ to $11 \mathrm{~mm}$.

\section{Acknowledgments}

This work was supported by the Korea Institute of Energy Technology Evaluation and Planning (KETEP) funded by the Ministry of Trade, Industry \& Energy (MOTIE) of the Republic of Korea (No. 20153010130460 and No. 20174010201310).

\section{Nomenclature}

C

Membrane distillation coefficient $\left[\mathrm{kg} / \mathrm{m}^{2} \mathrm{sPa}\right]$

$C_{p}$

Specific heat capacity $[\mathrm{kJ} / \mathrm{kmolK}]$

D

Diffusion coefficient $\left[\mathrm{m}^{2} \mathrm{~s}\right]$

$d_{h}$

Hydraulic diameter [m]

$h$

Heat transfer coefficient $\left[\mathrm{W} / \mathrm{m}^{2} \mathrm{~K}\right]$

$h_{c h}$

Channel height $[\mathrm{m}]$

$g$

Gravity $\left[\mathrm{m} / \mathrm{s}^{2}\right]$

$\Delta H$

Enthalpy of water evaporation $[\mathrm{J} / \mathrm{kg}]$

Permeate flux $\left[\mathrm{kg} / \mathrm{m}^{2} \mathrm{~h}\right]$

$k$

Thermal conductivity $[\mathrm{W} / \mathrm{mK}]$

$L \quad$ Channel length [m]

M

Molecular weight $[\mathrm{kg} / \mathrm{kmol}]$ 


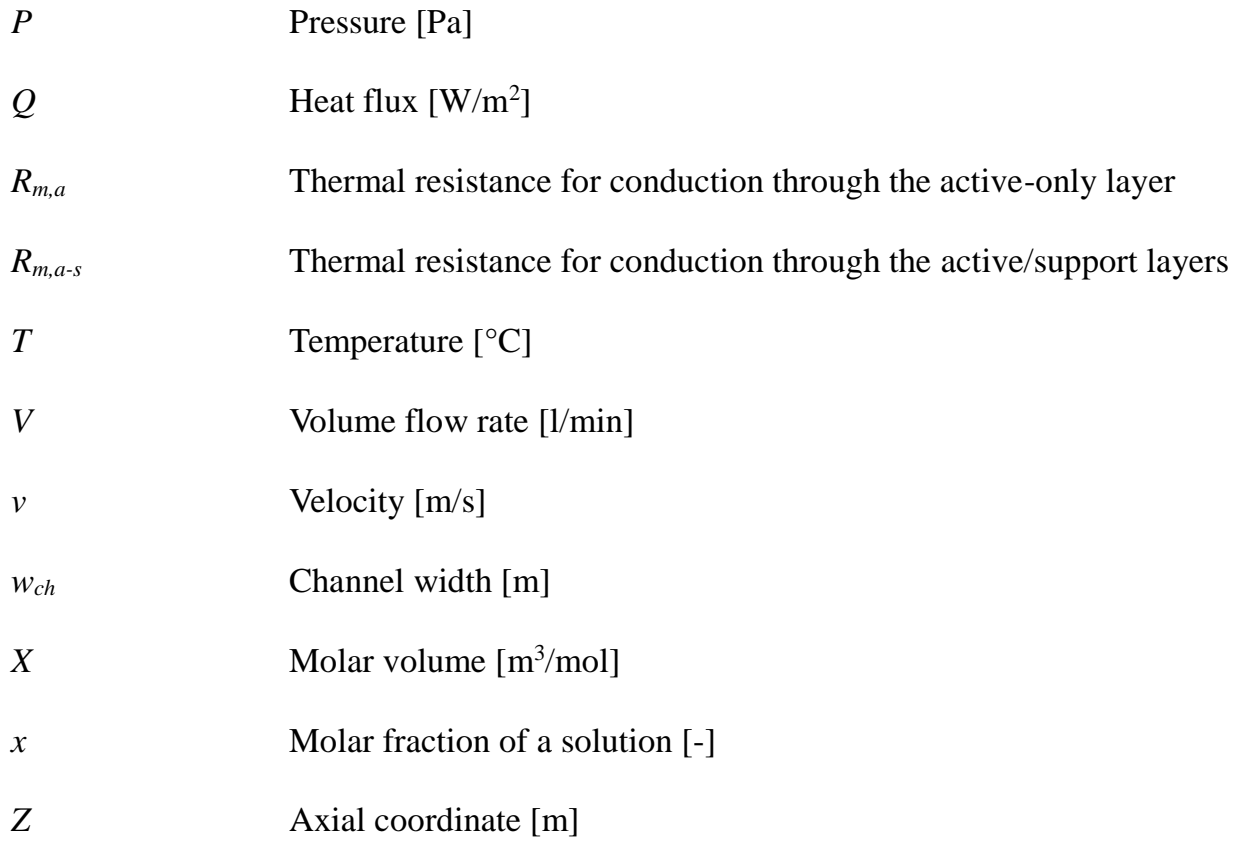

Kinematic viscosity $\left[\mathrm{m}^{2} / \mathrm{s}\right]$

\section{Subscripts}

$a$

$a g$
Active layer

Air gap 


$\begin{array}{ll}\text { air } & \text { Air } \\ a-s & \text { Active/support layer } \\ c & \text { Coolant } \\ f & \text { Feed } \\ g & \text { Gas } \\ l g & \text { Liquid gap } \\ m & \text { Mean, membrane or mesh } \\ p & \text { Membrane pore } \\ s & \text { Support layer } \\ s f & \text { Surface } \\ s p & \text { Spacer } \\ s p f & \text { Spacer filament } \\ v & \text { Vapor } \\ w & \text { Water }\end{array}$

\section{Reference}

[1] Y.-D. Kim, K. Thu, N. Ghaffour, K.C. Ng, Performance investigation of a solar-assisted direct contact membrane distillation system, J. Membr. Sci., 427 (2013) 345-364.

[2] K.W. Lawson, D.R. Lloyd, Membrane distillation, J. Membr. Sci., 124 (1997) 1-25.

[3] L.M. Camacho, L. Dumée, J. Zhang, J.-D. Li, M. Duke, J. Gomez, S. Gray, Advances in membrane distillation for water desalination and purification applications, Water, 5 (2013) 94-196.

[4] L.-H. Cheng, P.-C. Wu, J. Chen, Numerical simulation and optimal design of AGMD-based hollow fiber modules for desalination, Ind. Eng. Chem. Res., 48 (2009) 4948-4959.

[5] M. Khayet, J.I. Mengual, T. Matsuura, Porous hydrophobic/hydrophilic composite membranes: Application in desalination using direct contact membrane distillation, J. Membr. Sci., 252 (2005) 101-113.

[6] P. Peng, A.G. Fane, X. Li, Desalination by membrane distillation adopting a hydrophilic membrane, Desalination, 173 (2005) 45-54.

[7] C. Feng, R. Wang, B. Shi, G. Li, Y. Wu, Factors affecting pore structure and performance of poly(vinylidene fluoride-co-hexafluoro propylene) asymmetric porous membrane, J. Membr. Sci., 277 (2006) 55-64.

[8] R. Huo, Z. Gu, K. Zuo, G. Zhao, Preparation and properties of PVDF-fabric composite membrane for 
membrane distillation, Desalination, 249 (2009) 910-913.

[9] J.A. Prince, V. Anbharasi, T.S. Shanmugasundaram, G. Singh, Preparation and characterization of novel triple layer hydrophilic-hydrophobic composite membrane for desalination using air gap membrane distillation, Sep. Purif. Technol., 118 (2013) 598-603.

[10] M. Qtaishat, M. Khayet, T. Matsuura, Guidelines for preparation of higher flux hydrophobic/hydrophilic composite membranes for membrane distillation, J. Membr. Sci., 329 (2009) 193-200.

[11] D. Winter, J. Koschikowski, D. Düver, P. Hertel, U. Beuscher, Evaluation of MD process performance: Effect of backing structures and membrane properties under different operating conditions, Desalination, 323 (2013) 120-133.

[12] J.-G. Lee, Y.-D. Kim, W.-S. Kim, L. Francis, G. Amy, N. Ghaffour, Performance modeling of direct contact membrane distillation (DCMD) seawater desalination process using a commercial composite membrane, J. Membr. Sci., 478 (2015) 85-95.

[13] G.L. Liu, C. Zhu, C.S. Cheung, C.W. Leung, Theoretical and experimental studies on air gap membrane distillation, Heat Mass Transf., 34 (1998) 329-335.

[14] L. Francis, N. Ghaffour, A.A. Alsaadi, G.L. Amy, Material gap membrane distillation: A new design for water vapor flux enhancement, J. Membr. Sci., 448 (2013) 240-247.

[15] M. Essalhi, M. Khayet, Application of a porous composite hydrophobic/hydrophilic membrane in desalination by air gap and liquid gap membrane distillation: A comparative study, Sep. Purif. Technol., 133 (2014) 176-186.

[16] A.S. Alsaadi, N. Ghaffour, J.D. Li, S. Gray, L. Francis, H. Maab, G.L. Amy, Modeling of air-gap membrane distillation process: A theoretical and experimental study, J. Membr. Sci., 445 (2013) 53-65.

[17] J.-G. Lee, W.-S. Kim, Numerical study on multi-stage vacuum membrane distillation with economic evaluation, Desalination, 339 (2014) 54-67.

[18] A. Cipollina, M.G. Di Sparti, A. Tamburini, G. Micale, Development of a membrane distillation module for solar energy seawater desalination, Chem. Eng. Res. Des., 90 (2012) 2101-2121.

[19] A.R. Da Costa, A.G. Fane, D.E. Wiley, Spacer characterization and pressure drop modelling in spacer-filled channels for ultrafiltration, J. Membr. Sci., 87 (1994) 79-98.

[20] R.W. Schofield, A.G. Fane, C.J.D. Fell, Heat and mass transfer in membrane distillation, J. Membr. Sci., 33 (1987) 299-313.

[21] S. Al-Sharif, M. Albeirutty, A. Cipollina, G. Micale, Modelling flow and heat transfer in spacer-filled 
membrane distillation channels using open source CFD code, Desalination, 311 (2013) 103-112.

[22] J. Phattaranawik, R. Jiraratananon, A.G. Fane, C. Halim, Mass flux enhancement using spacer filled channels in direct contact membrane distillation, J. Membr. Sci., 187 (2001) 193-201.

[23] J. Phattaranawik, R. Jiraratananon, A.G. Fane, Effects of net-type spacers on heat and mass transfer in direct contact membrane distillation and comparison with ultrafiltration studies, J. Membr. Sci., 217 (2003) $193-206$.

[24] M. Khayet, T. Matsuura, Membrane Distillation, Elsevier, Amsterdam, 2011.

[25] A.M. Alklaibi, N. Lior, Transport analysis of air-gap membrane distillation, J. Membr. Sci., 255 (2005) 239-253.

[26] F.A. Banat, J. Simandl, Membrane distillation for dilute ethanol: Separation from aqueous streams, J. Membr. Sci., 163 (1999) 333-348.

[27] S. Kimura, S.I. Nakao, S.I. Shimatani, Transport phenomena in membrane distillation, J. Membr. Sci., 33 (1987) 285-298.

[28] S.M. Shim, J.G. Lee, W.S. Kim, Performance simulation of a multi-VMD desalination process including the recycle flow, Desalination, 338 (2014) 39-48.

[29] M. Khayet, Membranes and theoretical modeling of membrane distillation: A review, Adv. Colloid Interface Sci., 164 (2011) 56-88.

[30] J.-G. Lee, W.-S. Kim, Numerical modeling of the vacuum membrane distillation process, Desalination, 331 (2013) 46-55.

[31] V.V. Ugrozov, I.B. Elkina, V.N. Nikulin, L.I. Kataeva, Theoretical and experimental research of liquid-gap membrane distillation process in membrane module, Desalination, 157 (2003) 325-331.

[32] Y.A. Cengel, Heat transfer: A practical approach, 2nd ed., McGraw Hill, 2002.

[33] R.K. MacGregor, A.F. Emery, Free convection through vertical plane layers - Moderate and high Prandtl number fluids, J. Heat Transfer, 91 (1969) 391-401.

[34] L.-H. Cheng, P.-C. Wu, J. Chen, Modeling and optimization of hollow fiber DCMD module for desalination, J. Membr. Sci., 318 (2008) 154-166.

[35] M.H. Sharqawy, J.H. Lienhard, S.M. Zubair, Thermophysical properties of seawater: a review of existing correlations and data, Desalin. Water Treat., 16 (2010) 354-380.

[36] M. Essalhi, M. Khayet, Surface segregation of fluorinated modifying macromolecule for hydrophobic/hydrophilic membrane preparation and application in air gap and direct contact membrane distillation, J. Membr. Sci., 417-418 (2012) 163-173. 
[37] N.C. Markatos, K.A. Pericleous, Laminar and turbulent natural convection in an enclosed cavity, Int. J. Heat Mass Transfer, 27 (1984) 755-772.

[38] K.J. King, Turbulent natural convection in rectangular air cavities, in: Queen Mary College, University of London, UK, 1989.

[39] Y.-D. Kim, K. Thu, K.C. Ng, G.L. Amy, N. Ghaffour, A novel integrated thermal-/membrane-based solar energy-driven hybrid desalination system: Concept description and simulation results, Water Res., 100 (2016) 7 19.

[40] Y.-D. Kim, K. Thu, S.-H. Choi, Solar-assisted multi-stage vacuum membrane distillation system with heat recovery unit, Desalination, 367 (2015) 161-171.

[41] J.-G. Lee, W.-S. Kim, J.-S. Choi, N. Ghaffour, Y.-D. Kim, A novel multi-stage direct contact membrane distillation module: Design, experimental and theoretical approaches, Water Res., 107 (2016) 47-56.

[42] A.M. Alklaibi, N. Lior, Heat and mass transfer resistance analysis of membrane distillation, J. Membr. Sci., 282 (2006) 362-369.

\section{Table captions}

Table 1 Specifications of the spacer.

Table 2 Characteristics of the PTFE/PP composite membrane.

Table 3 Specifications of the membrane module.

\section{Figure captions}

Fig. 1. Schematic diagram of the heat and mass transfer mechanisms in (a) AGMD and (b) LGMD.

Fig. 2. SEM micrographs of a commercial PTFE/PP composite membrane. Clockwise from top left: 100×, 500×, $1,000 \times$ and 10,000x magnifications.

Fig. 3. Schematic of heat transfer through the composite membrane in AGMD.

Fig. 4. Schematic of mass transfer through the composite membrane in AGMD.

Fig. 5. Schematic of heat transfer through the composite membrane in LGMD.

Fig. 6. Schematic of mass transfer through the composite membrane in LGMD.

Fig. 7. Experimental (symbol) $[14,16]$ and simulated (line) permeate fluxes in AGMD and LGMD with different gap sizes $\left(\delta_{\text {gap }}=9,13 \mathrm{~mm}\right)$ at $T_{f}=40-80^{\circ} \mathrm{C}, T_{c}=20^{\circ} \mathrm{C}$, and $V_{f}=V_{c}=1.5 \mathrm{l} / \mathrm{min}$. 
Fig. 8. Effect of the feed temperature $\left(T_{f}\right)$ in the range of $40-70{ }^{\circ} \mathrm{C}$ on (a) AGMD and (b) LGMD permeate fluxes at $V_{f}=2.5 \mathrm{l} / \mathrm{min}, V_{c}=1.5 \mathrm{l} / \mathrm{min}, T_{c}=25^{\circ} \mathrm{C}$, and $\varepsilon_{s}=0.42$.

Fig. 9. Effect of the feed flow rate $\left(V_{f}\right)$ in the range of $0.5-5.01 / \mathrm{min}$ on (a) AGMD and (b) LGMD permeate fluxes at $V_{p}=1.5 \mathrm{l} / \mathrm{min}, T_{f}=70^{\circ} \mathrm{C}, T_{c}=25^{\circ} \mathrm{C}$, and $\varepsilon_{s}=0.42$.

Fig. 10. Effect of the coolant temperature $\left(T_{c}\right)$ in the range of $10-30^{\circ} \mathrm{C}$ on (a) AGMD and (b) LGMD permeate fluxes at $V_{f}=2.5 \mathrm{l} / \mathrm{min}, V_{c}=1.51 / \mathrm{min}, T_{f}=70^{\circ} \mathrm{C}$, and $\varepsilon_{s f}=0.42$.

Fig. 11. Effect of the coolant flow rate $\left(V_{c}\right)$ in the range of $0.5-5.01 / \mathrm{min}$ on (a) AGMD and (b) LGMD permeate fluxes at $V_{f}=2.51 / \mathrm{min}, T_{f}=70^{\circ} \mathrm{C}, T_{c}=25^{\circ} \mathrm{C}$, and $\varepsilon_{s}=0.42$.

Fig. 12. Effect of the surface porosity $\left(\varepsilon_{s}\right)$ in the range of $0.1-0.7$ on (a) AGMD and (b) LGMD permeate fluxes at $V_{f}=2.5 \mathrm{l} / \mathrm{min}, V_{c}=1.5 \mathrm{l} / \mathrm{min}, T_{f}=70^{\circ} \mathrm{C}$, and $T_{c}=25^{\circ} \mathrm{C}$. 
Table 1

Specifications of the spacer.

\begin{tabular}{lc}
\hline Material & PP \\
\hline Spacer thickness, $\delta_{s p}(\mathrm{~mm})$ & 0.8 \\
Filament diameter, $d_{s p f}(\mathrm{~mm})$ & 0.4 \\
Angle between filaments, $\theta(\mathrm{deg})$ & 90 \\
Mesh size, $l_{m}(\mathrm{~mm})$ & 2 \\
\hline
\end{tabular}


Table 2

Characteristics of the PTFE/PP composite membrane.

\begin{tabular}{lcc}
\hline Material & PTFE & PP \\
\hline Thickness, $\delta(\mu \mathrm{m})$ & 20 & 80 \\
Porosity, $\varepsilon(\%)$ & 70 & 34 \\
Mean pore size, $r_{p}(\mu \mathrm{m})$ & 0.5 & 0.1 \\
Liquid entry pressure, $L E P_{w}(\mathrm{kPa})$ & 207 & 160 \\
\hline
\end{tabular}




\section{Table 3}

Specifications of the membrane module.

\begin{tabular}{ll}
\hline Channel height, $h_{c h}(\mathrm{~m})$ & 0.002 \\
Channel width, $w_{c h}(\mathrm{~m})$ & 0.05 \\
Channel length, $L(\mathrm{~m})$ & 0.1 \\
Air/liquid gap thickness, $\delta(\mathrm{mm})$ & $1-13$ \\
\hline
\end{tabular}




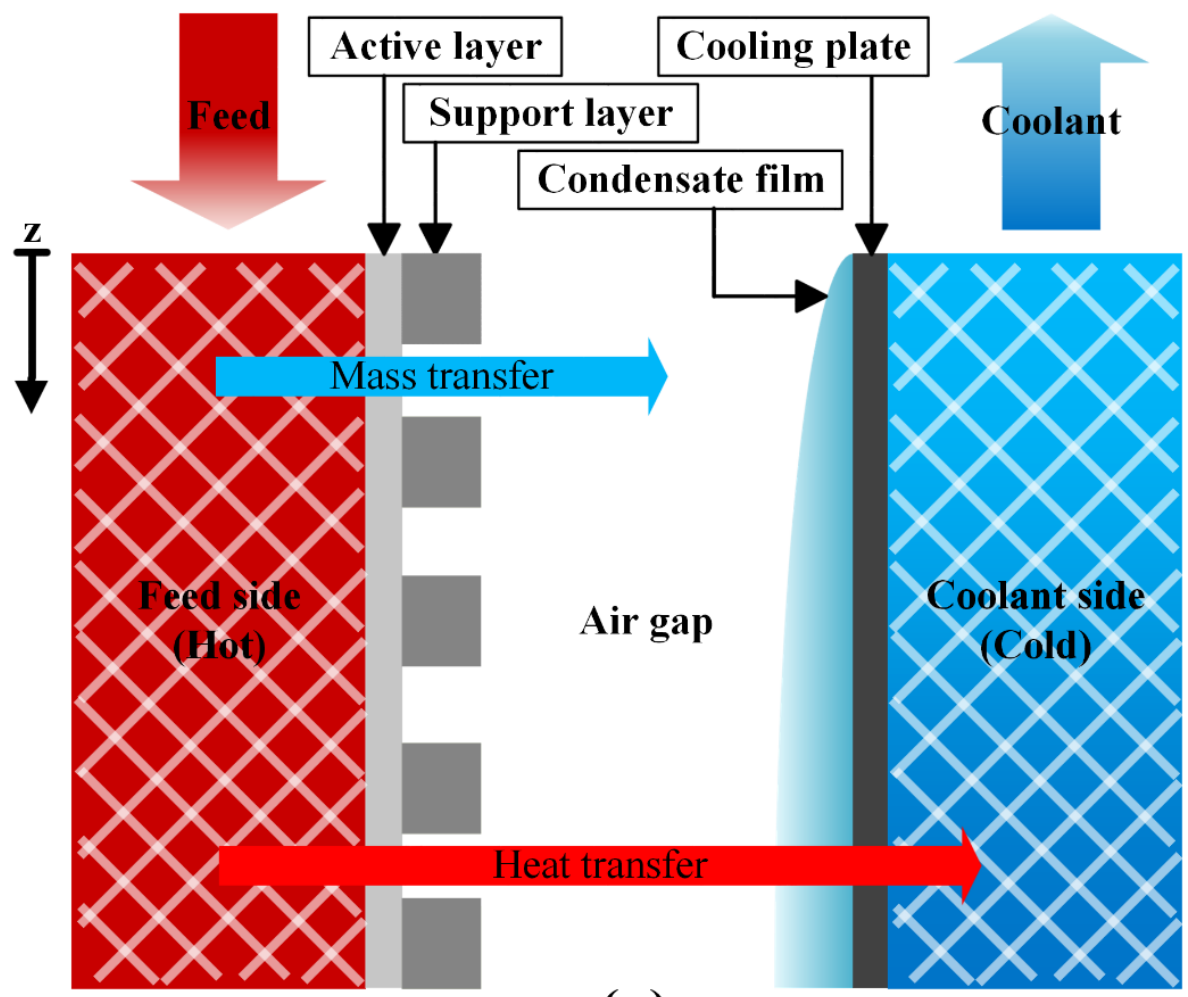

(a)

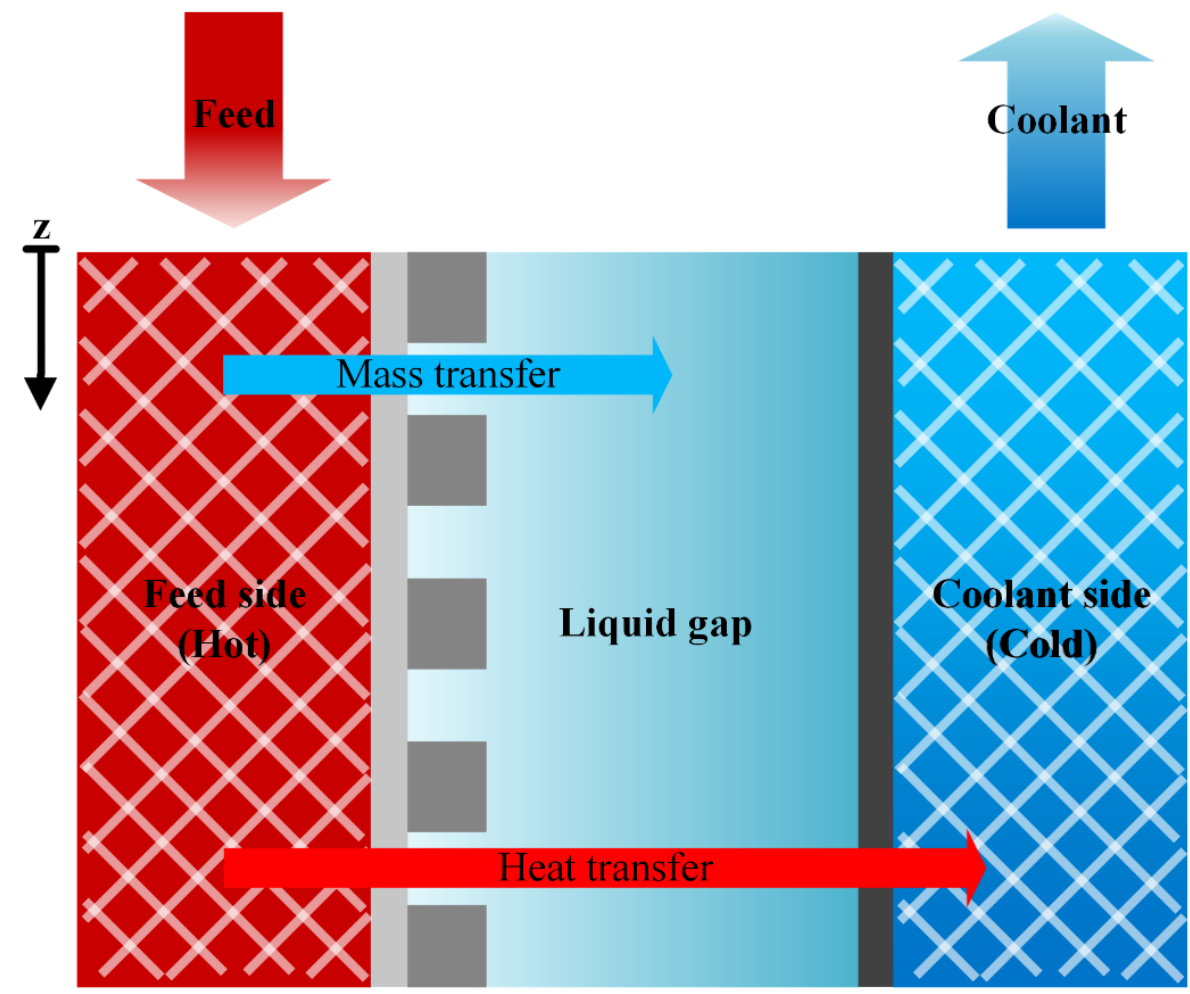

(b)

Fig. 1 


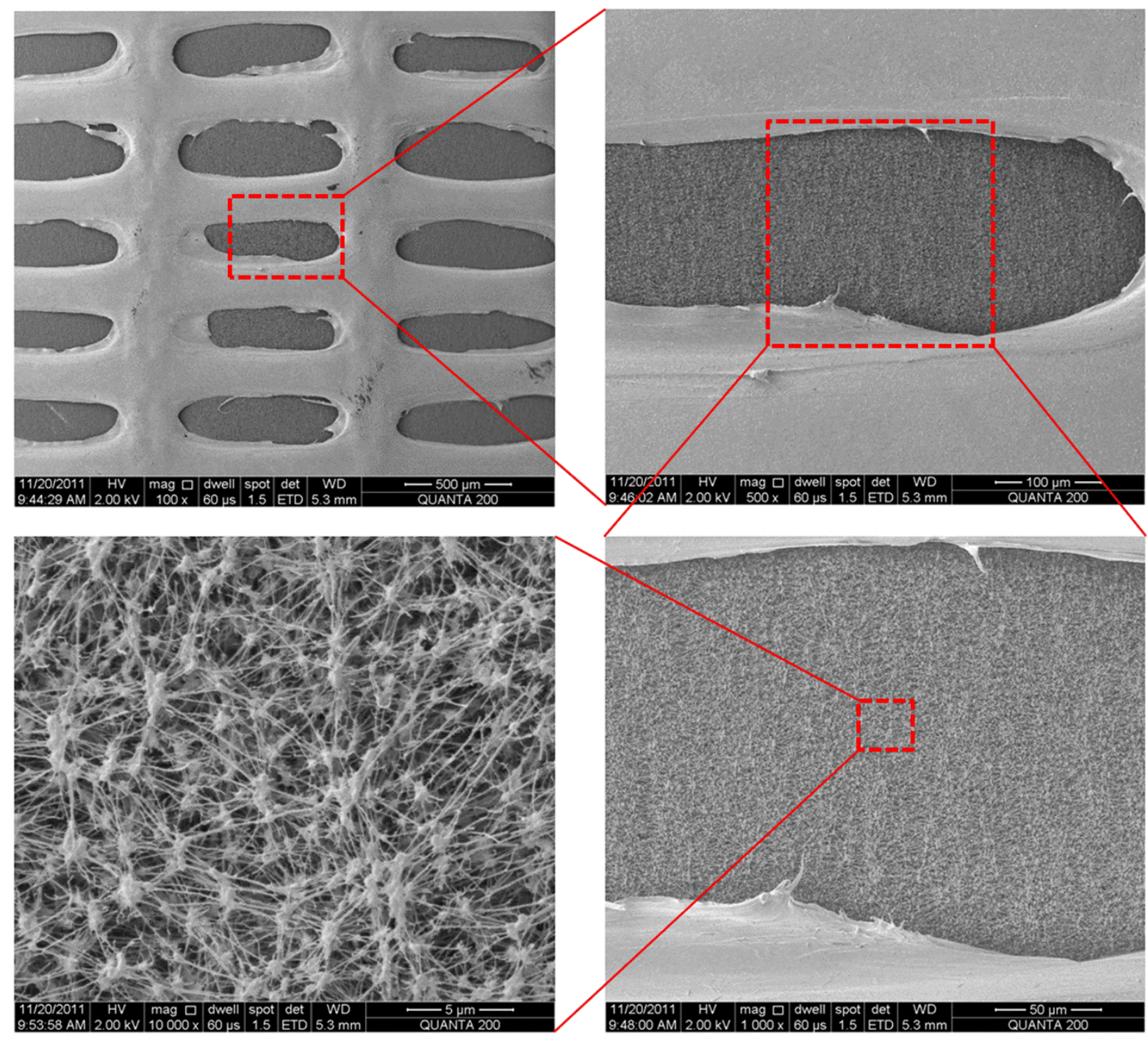

Fig. 2 


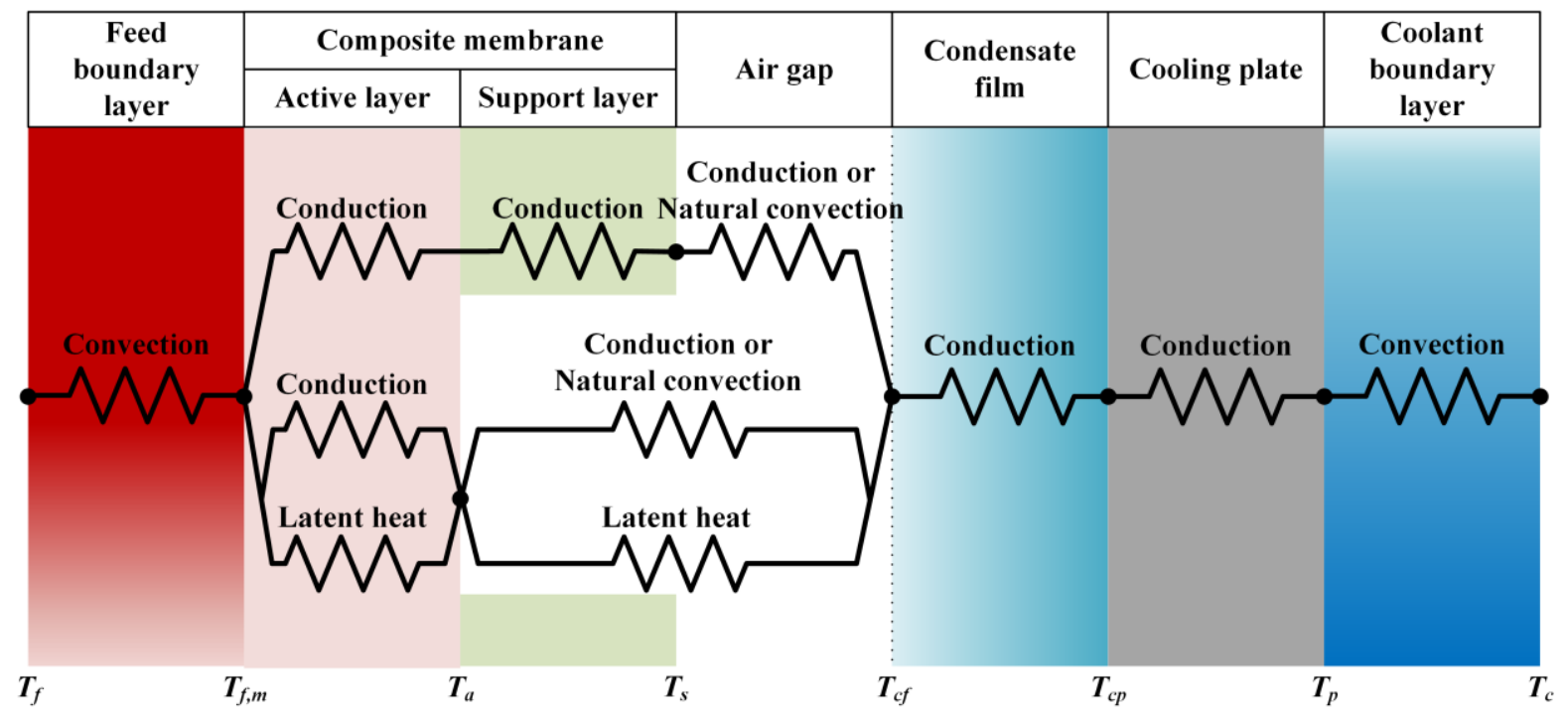

Fig. 3 


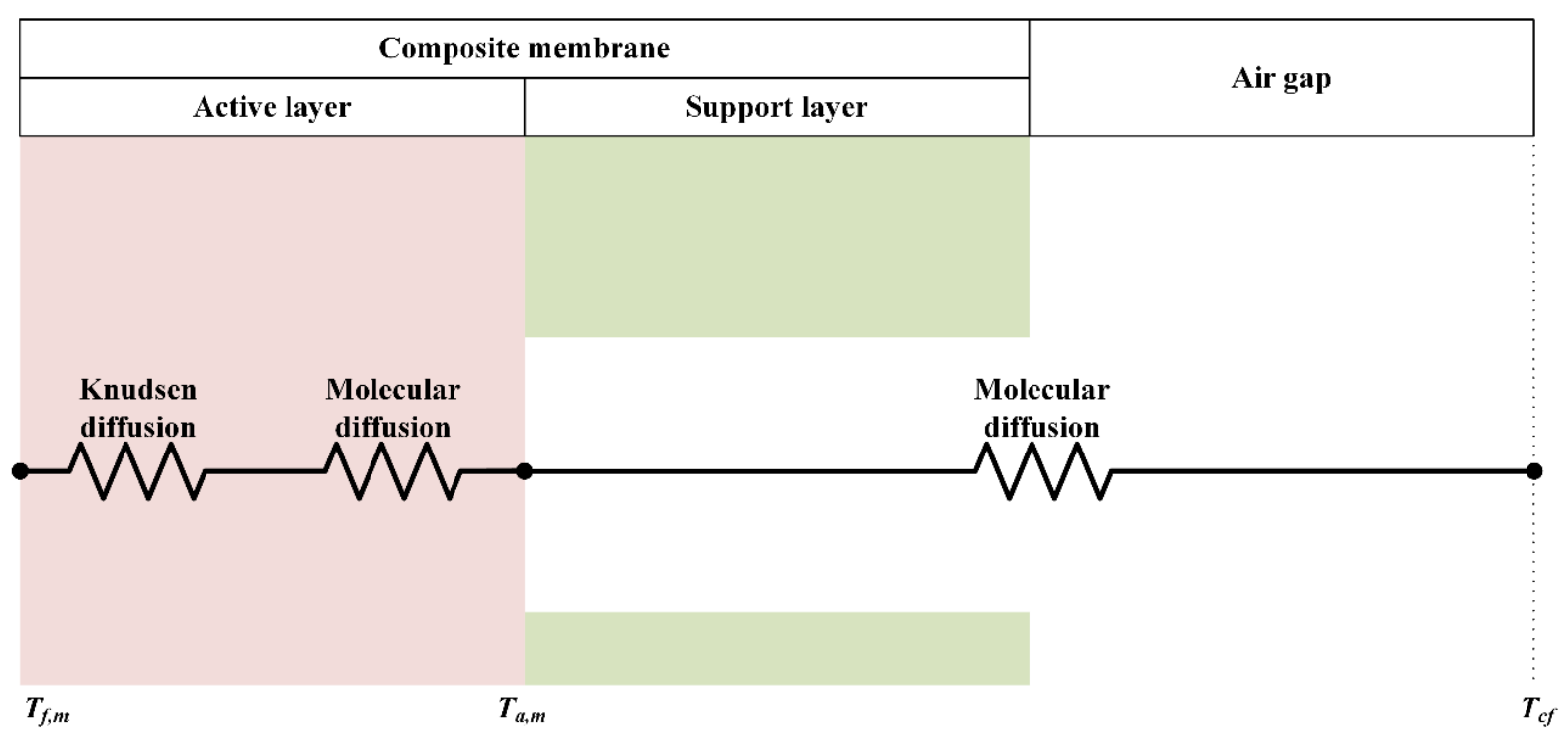

Fig. 4 


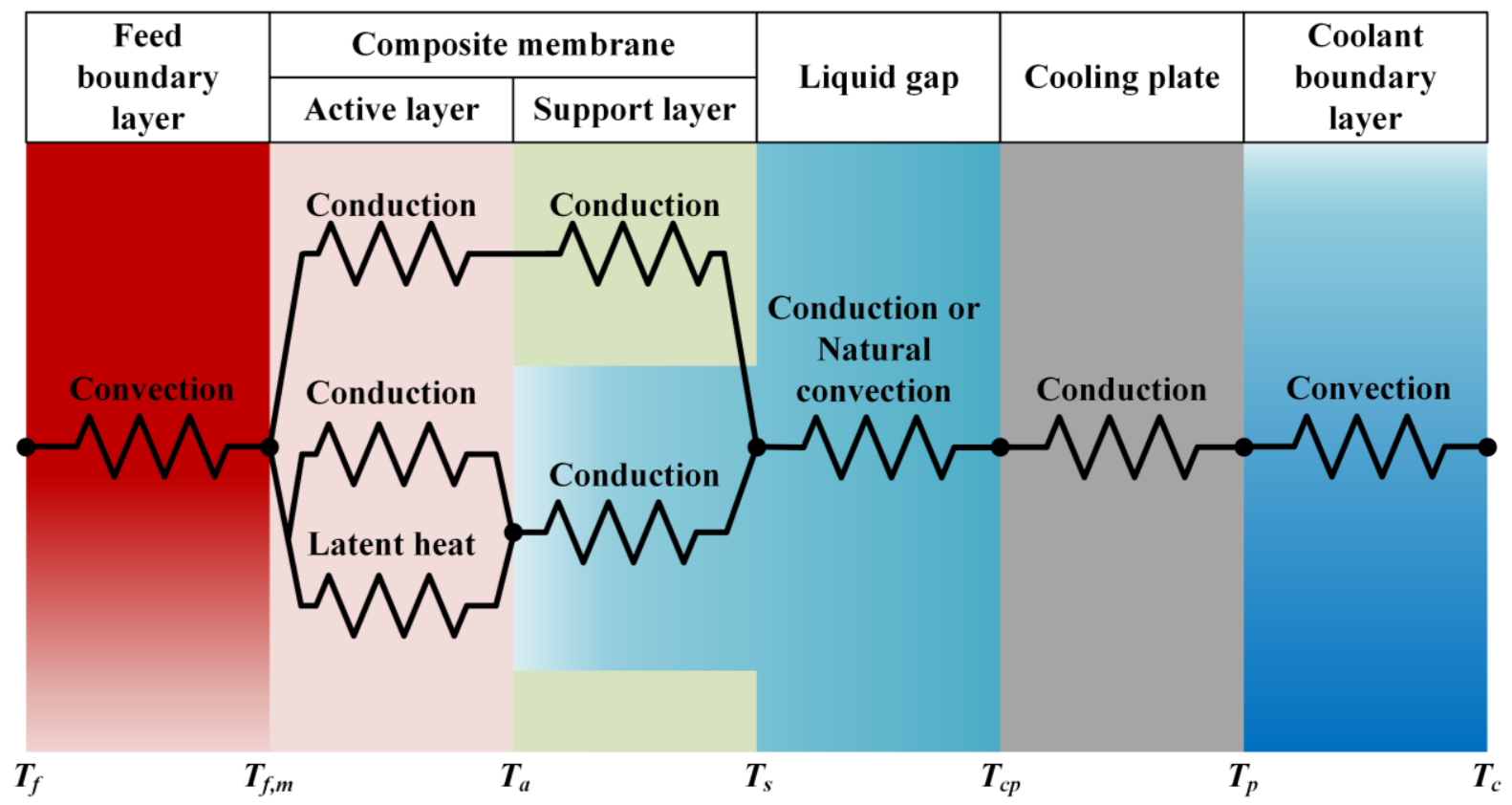

Fig. 5 


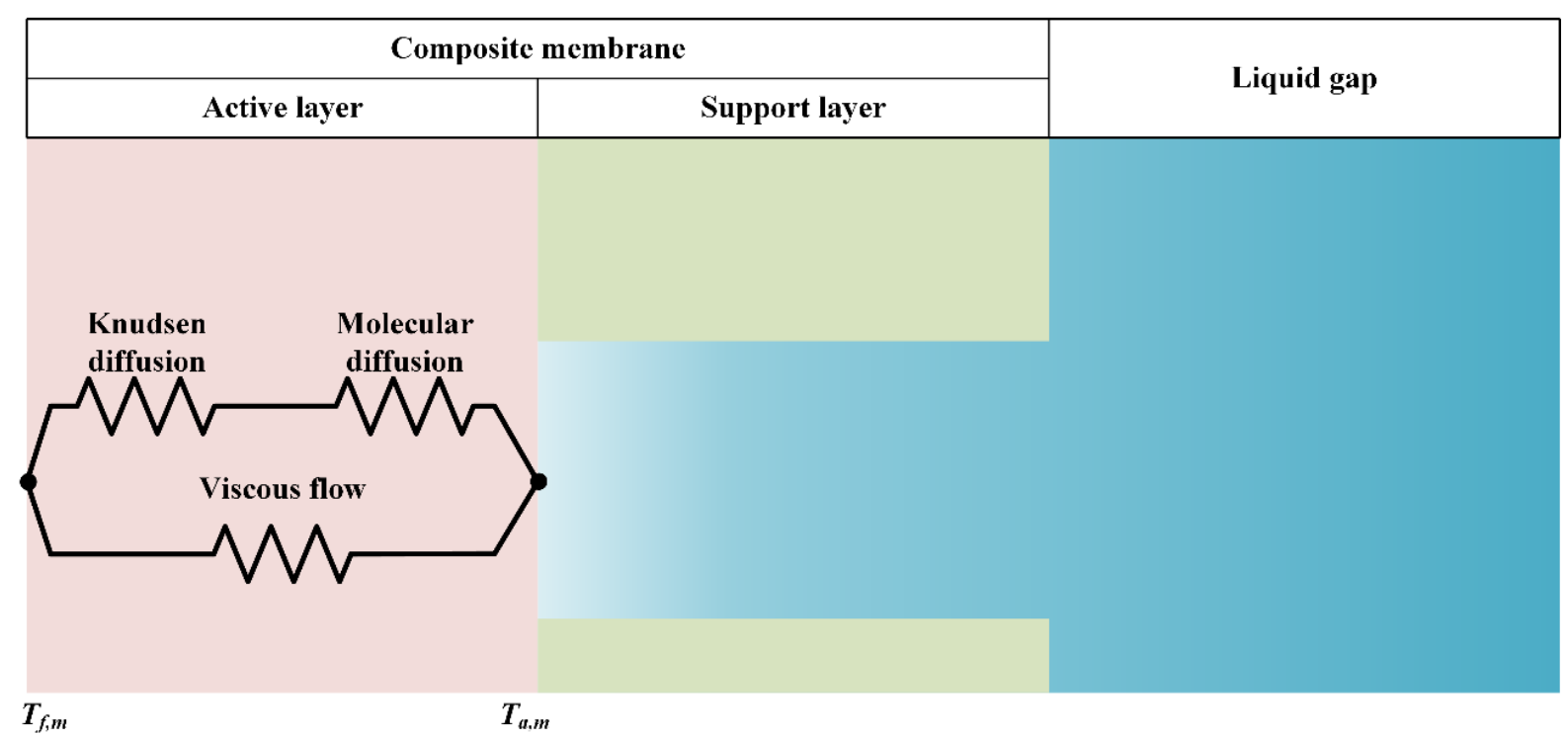

Fig. 6 


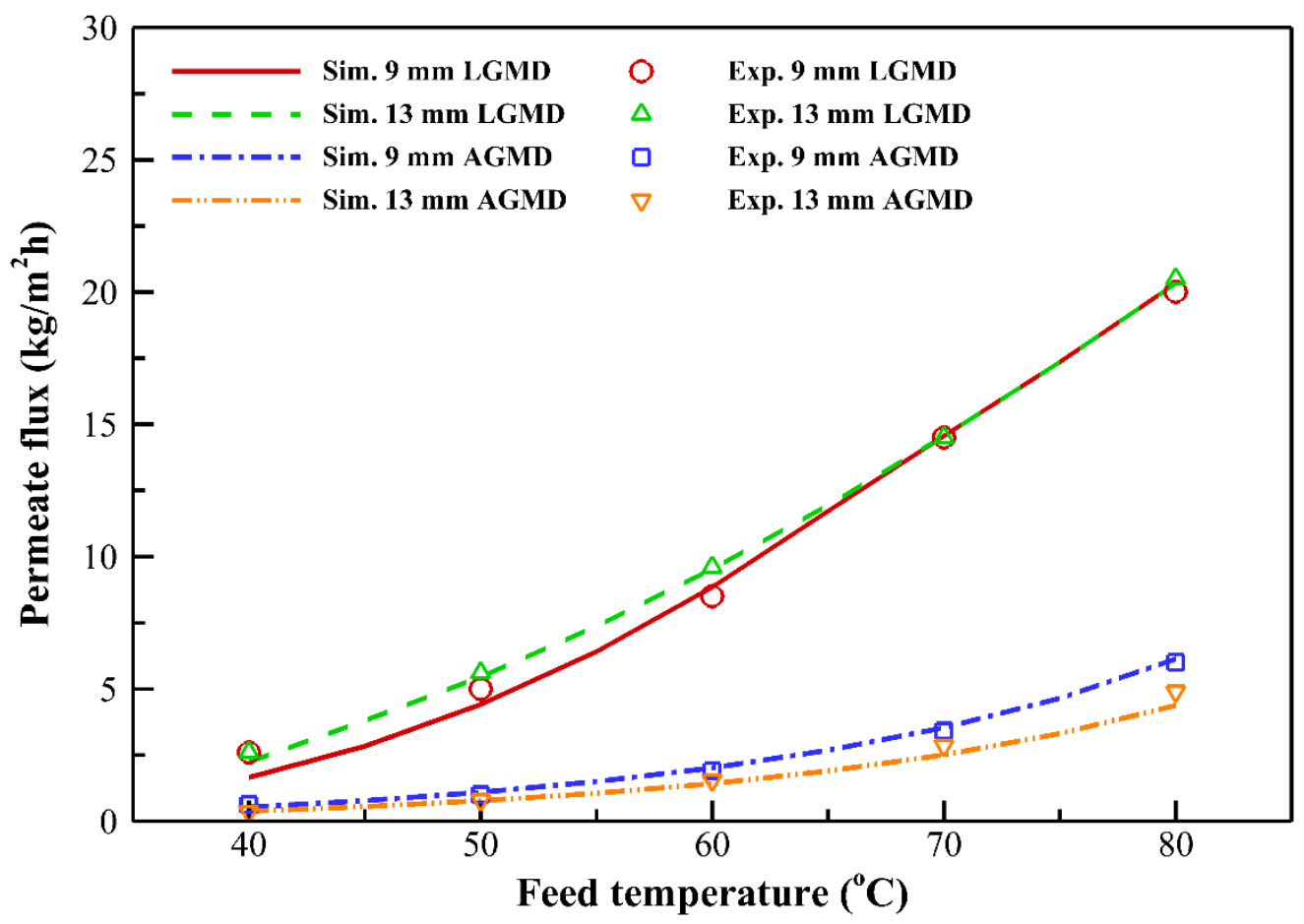

Fig. 7 

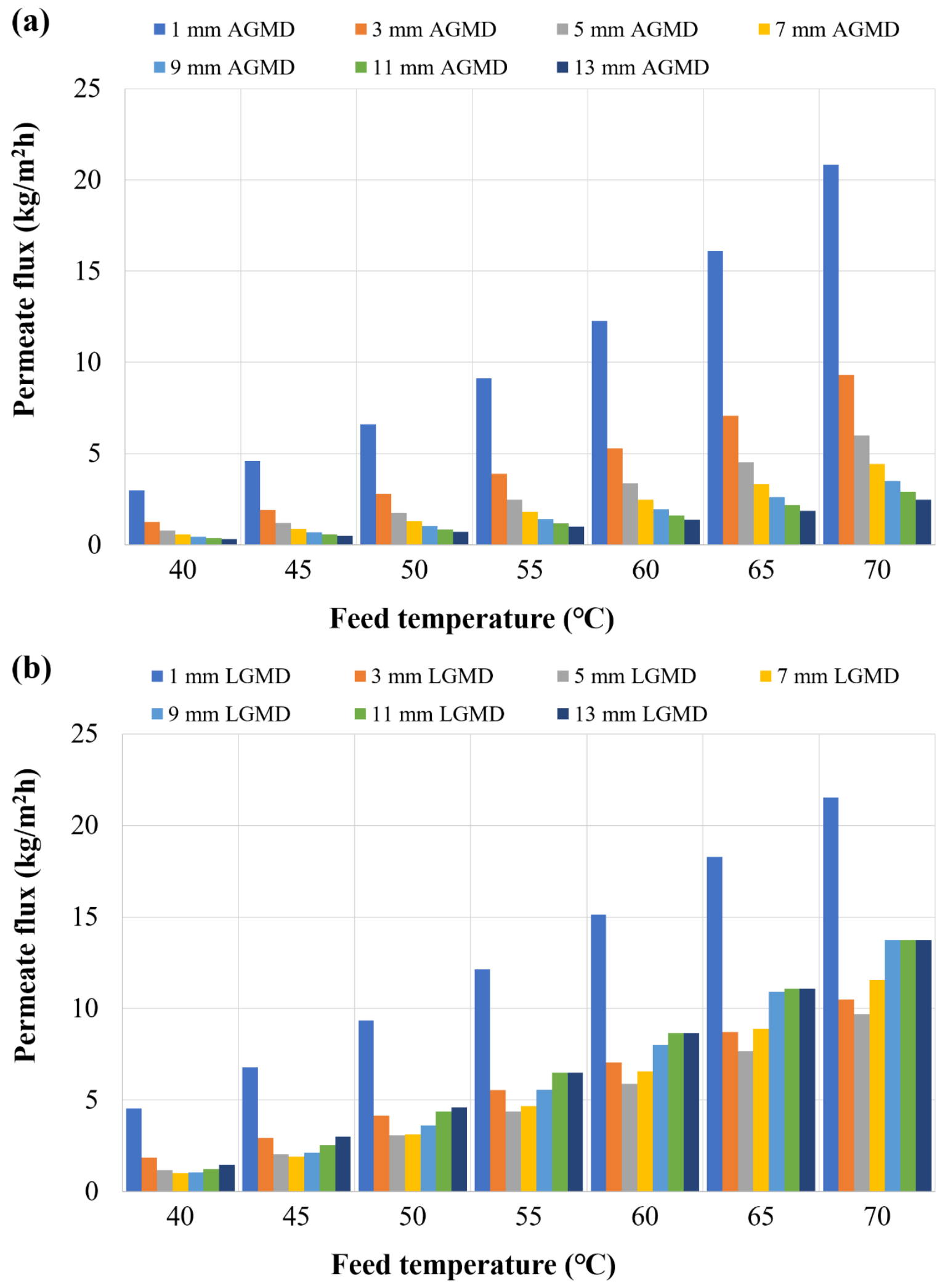

Fig. 8 

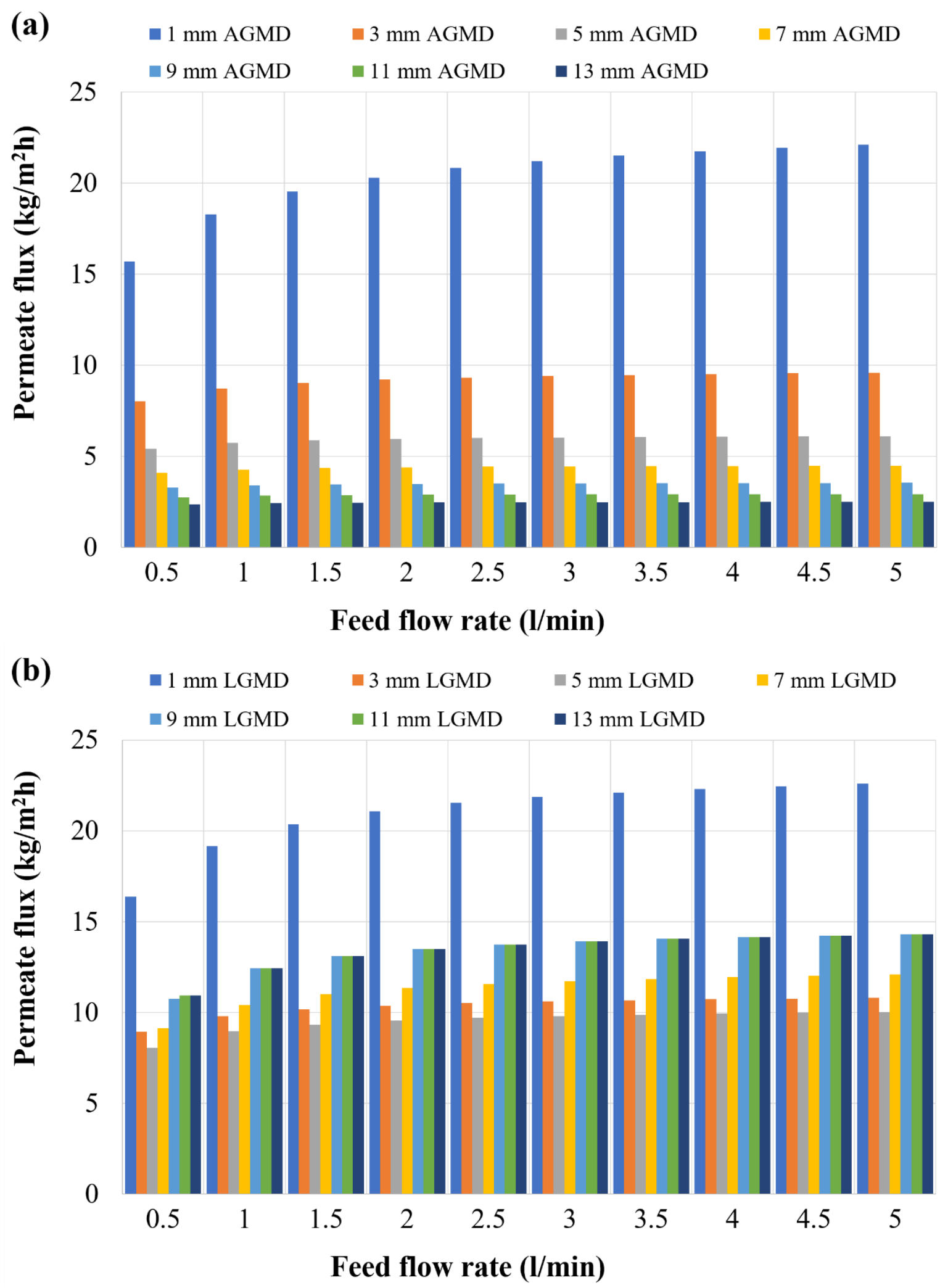

Fig. 9 

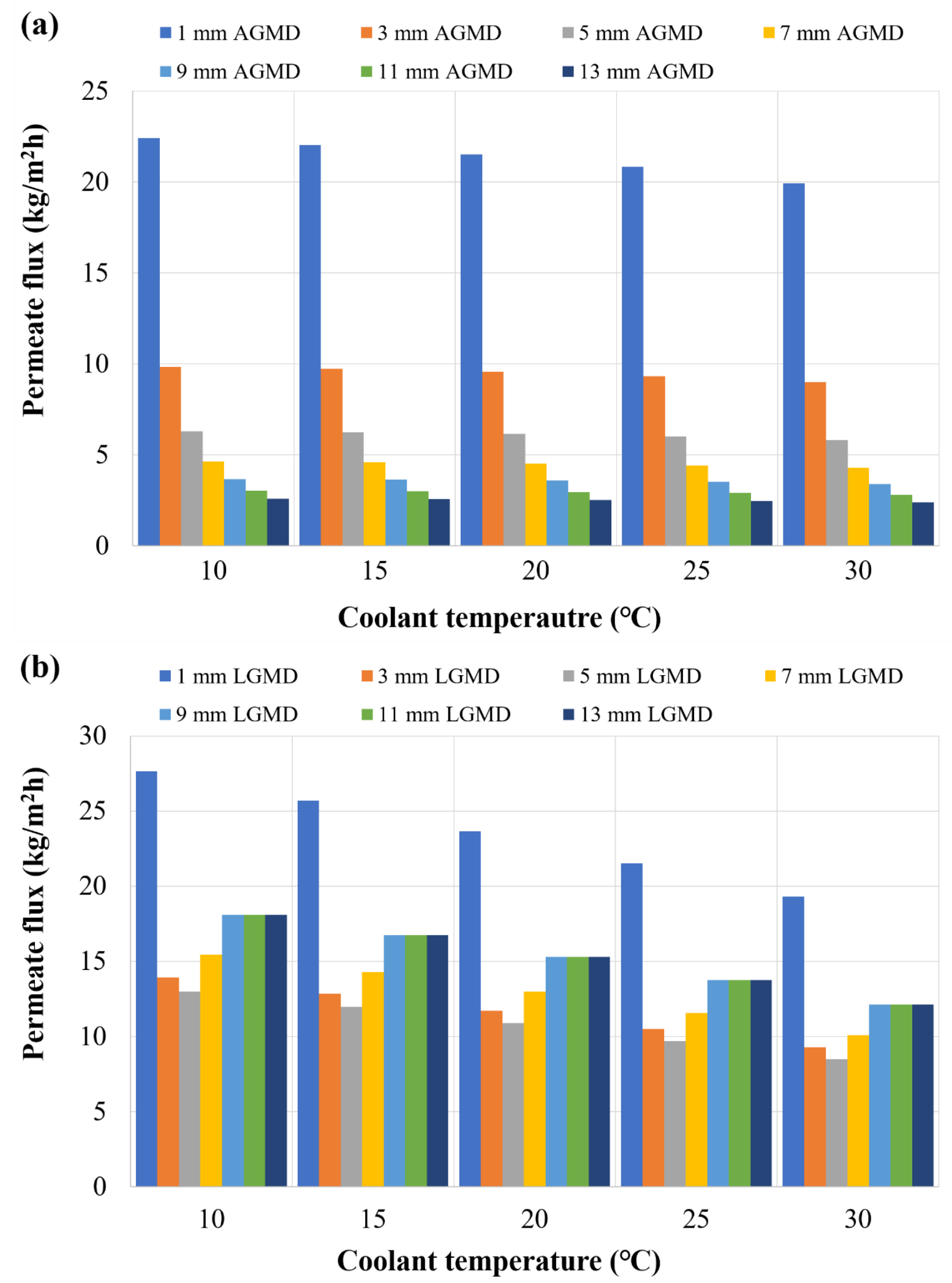

Fig. 10 

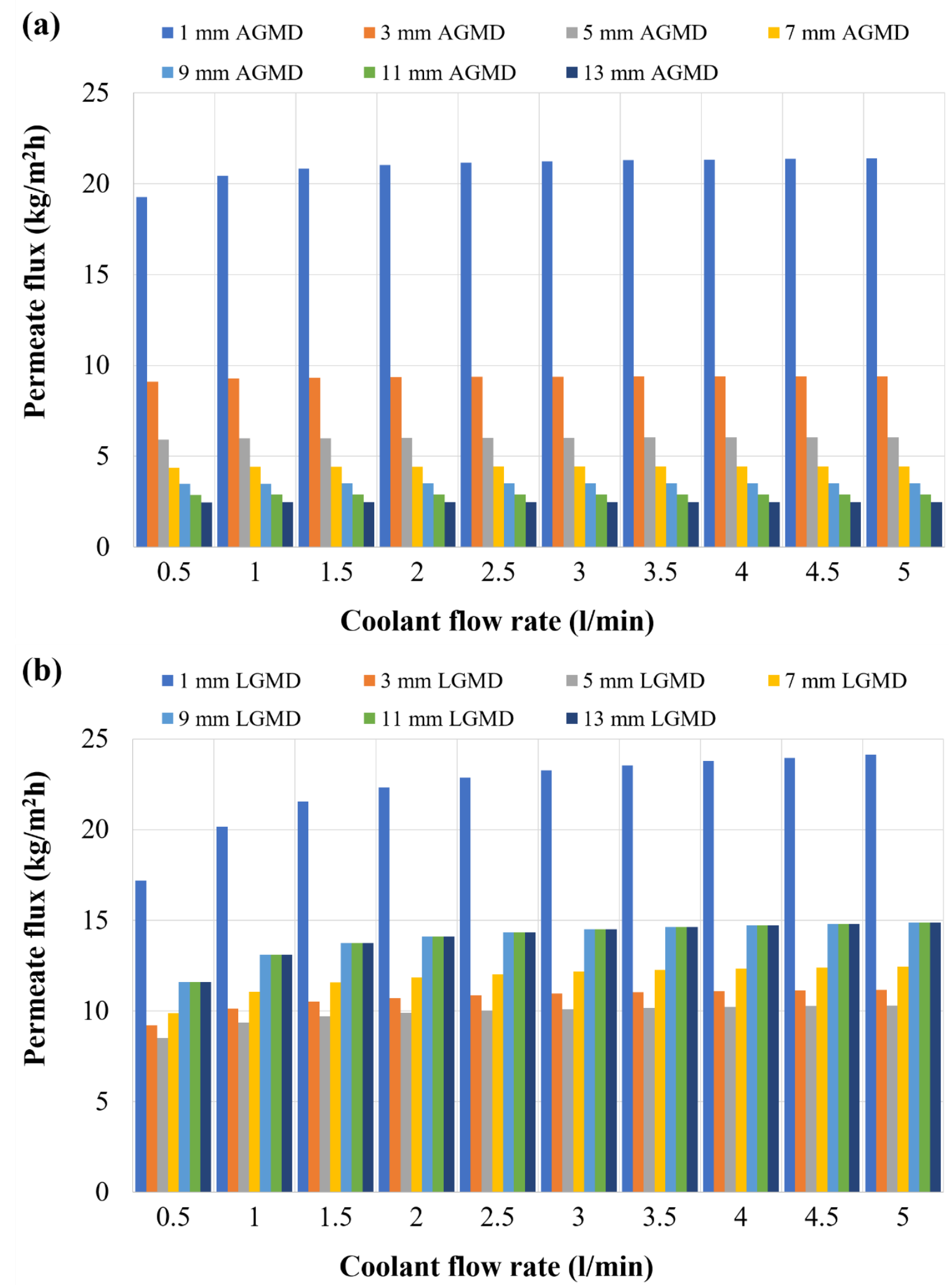

Fig. 11 

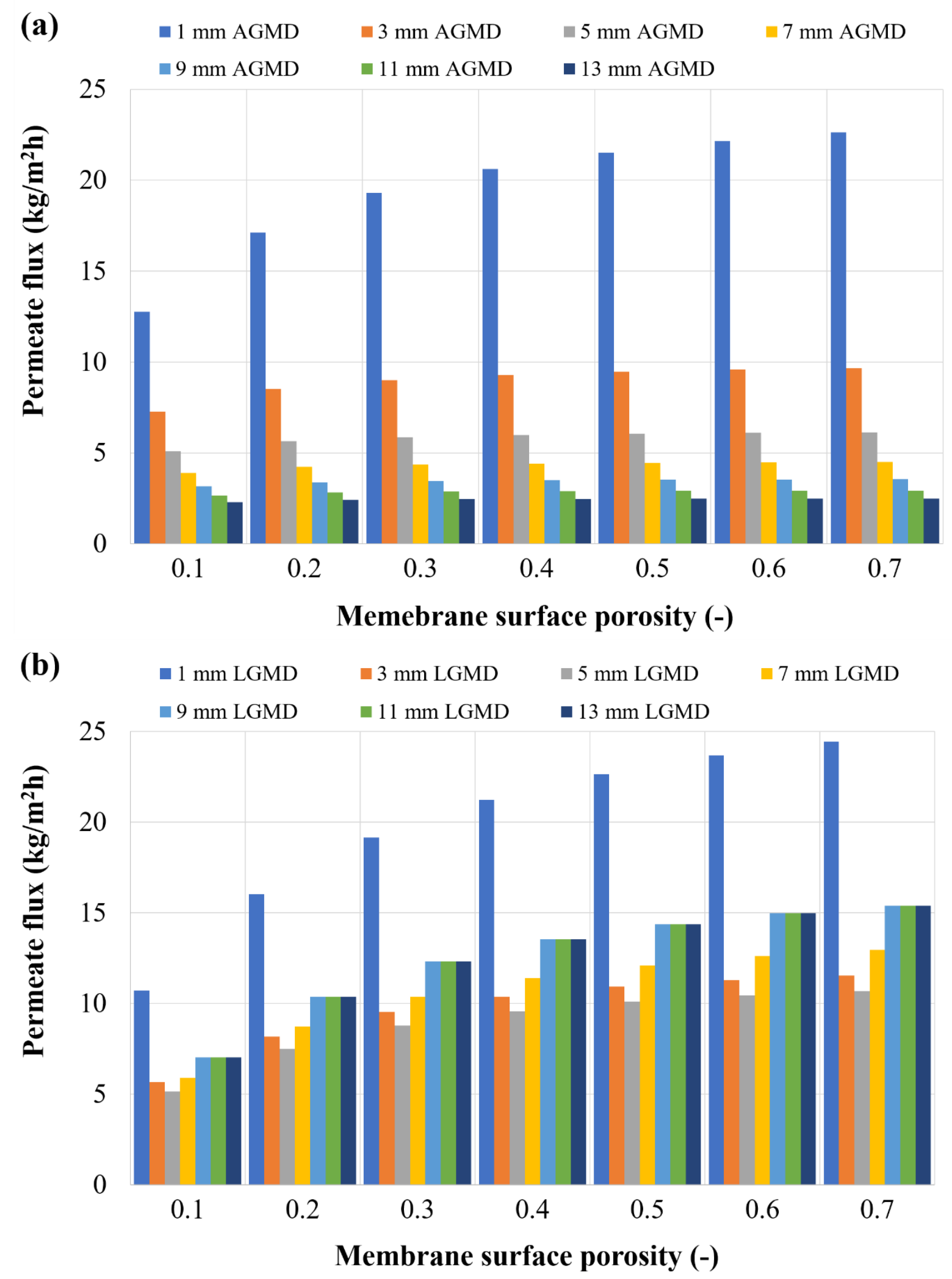

Fig. 12 